\title{
GFl1 downregulation promotes inflammation-linked metastasis of colorectal cancer
}

\author{
Wenjing Xing ${ }^{1,2,7}$, Yun Xiao ${ }^{3,7}$, Xinliang Lu ${ }^{1,2,4}$, Hongyan Zhu ${ }^{1,2}$, Xiangchuan $\mathrm{He}^{1,2}$, Wei Huang ${ }^{1,2}$, Elsa S Lopez ${ }^{5}$, Jerry Wong ${ }^{5}$, \\ Huanyu Ju ${ }^{1,2}$, Linlu Tian ${ }^{1,2}$, Fengmin Zhang ${ }^{2}$, Hongwei $\mathrm{Xu}^{1,2}$, Sheng Dian Wang ${ }^{4}$, Xia Li ${ }^{*}, 3$, Michael Karin ${ }^{\star, 5}$ and Huan Ren ${ }^{\star, 1,2,6}$
}

Inflammation is frequently associated with initiation, progression, and metastasis of colorectal cancer (CRC). Here, we unveil a CRC-specific metastatic programme that is triggered via the transcriptional repressor, GFI1. Using data from a large cohort of clinical samples including inflammatory bowel disease and CRC, and a cellular model of CRC progression mediated by cross-talk between the cancer cell and the inflammatory microenvironment, we identified GFI1 as a gating regulator responsible for a constitutively activated signalling circuit that renders CRC cells competent for metastatic spread. Further analysis of mouse models with metastatic CRC and human clinical specimens reinforced the influence of GFI1 downregulation in promoting CRC metastatic spread. The novel role of GFI1 is uncovered for the first time in a human solid tumour such as CRC. Our results imply that GFI1 is a potential therapeutic target for interfering with inflammation-induced CRC progression and spread.

Cell Death and Differentiation (2017) 24, 929-943; doi:10.1038/cdd.2017.50; published online 7 April 2017

Chronic inflammation is an important risk factor for colorectal cancer $(\mathrm{CRC})$ development and progression. ${ }^{1-3}$ Colitisassociated CRC shows more rapid progression, lower sensitivity to treatment and higher mortality than sporadic CRC. ${ }^{4}$ The tumour microenvironment contains cytokines, chemokines, inflammatory mediators, and so on, which have critical roles in almost every stage of progression to malignancy and metastasis. ${ }^{5-11}$ Approximately $50 \%$ of CRC patients develop metastatic disease, and only a minority of patients who undergo resection of metastases attain longterm survival. ${ }^{12}$

CRC progression to metastatic disease is a multi-step process involving extensive tumour-stroma cross-talk. Potent metastasis-promoting factors, including cytokines and extracellular matrix (ECM) proteins, may trigger epithelial mesenchymal transition (EMT), which drives cancer cell dissemination. ECM-degrading proteases and the c-MET, Notch, and TGF $\beta$ signalling pathways regulate tumour-stroma interactions and metastasis. ${ }^{13-15}$ Among these, TGF $\beta$ signalling is essential for the metastasis of CRC cells. Mice treated with a TGF $\beta$ R1 inhibitor were resilient to metastasis formation. ${ }^{15}$ Within the tumour microenvironment, amplified cyclo-oxygenase (COX)converted prostaglandin $E_{2}\left(P G E_{2}\right)$ further induces the secretion of IL6, IL8, VEGF, iNOS, MMP-2, and MMP-9, leading to increased tumour invasion and metastasis. ${ }^{16} \mathrm{PGE}_{2}$ exerts its effect by binding to EP receptors. Recent studies have shown that $\mathrm{PGE}_{2}-\mathrm{EP} 2$ signalling in tumour-infiltrating neutrophils promotes CRC cell growth via amplifying inflammation and shaping the tumour microenvironment. ${ }^{17,18}$ Moreover, tumour-associated macrophages (TAMs) are a major component promoting cancer progression in many aspects. The association between high TAMs and poor prognosis is observed in CRC. ${ }^{6}$ Nevertheless, tumour-stroma cross-talk during metastatic progression is highly complex, and the signalling events that control metastasis may be stagespecific. Eventually, potent microenvironmental factors may initiate a programme in which responsive cancer cells are selected as metastatic initiators that may travel to a secondary site and establish metastatic growth. ${ }^{19}$

Transcription factors (TF) have key roles in determining cell fate and behaviour. Given a significant link between inflammatory bowel disease (IBD) and $\mathrm{CRC},{ }^{20}$ we aimed to define key TF-regulated networks that may mediate transition programmes during CRC progression by analysing data sets from a large cohort of clinical specimens (Supplementary Figure S1). ${ }^{21}$ We thus defined a 24-core TF-regulated network comprising inflammation- and/or CRC-related genes. ${ }^{21}$ To validate the TF network in a cellular model, we applied an inflammation-promoting culture medium, ${ }^{22}$ LSMCM (LPSstimulated Monocyte Conditioned Medium), derived from human THP1 cells, to a series of CRC cell lines (Supplementary Figure S2A). LSMCM exposure triggered changes in CRC cell behaviour, including the EMT, and greatly increased cell migration and invasion. ${ }^{21}$ The expression of two

\footnotetext{
${ }^{1}$ Department of Immunology, Harbin Medical University, Harbin 150081, China; ${ }^{2}$ Immunity \& Infection Key laboratory of Heilongjiang Province, Harbin 150081 , China; ${ }^{3}$ Department of Bioinformatics, College of Bioinformatics, Harbin Medical University, Harbin 150081, China; ${ }^{4}$ Center of Infection and Immunity, Institute of Biophysics, Chinese Academy of Sciences, Beijing, China; ${ }^{5}$ Laboratory of Gene Regulation and Signal Transduction, Departments of Pharmacology and Pathology, School of Medicine, University of California, San Diego, 9500 Gilman Drive, La Jolla, CA, 92093, USA and ${ }^{6}$ College of basic medicine, Shanghai University Of Medicine \& Health Sciences, Shanghai 201318, China

*Corresponding author: H Ren, Department of Immunology, Harbin Medical University, 157 Baojian Road, room409, Molecular\&Biology Building, Harbin, 150081, China. Tel: +86 451 86674566; Fax: +86 451 86697322; E-mail: huanren2009@126.com

or M Karin, Laboratory of Gene Regulation and Signal Transduction, Departments of Pharmacology and Pathology, School of Medicine, University of California, San Diego, 9500 Gilman Drive, La Jolla, CA, 92093, USA. Tel: +858 534 1361; Fax: +858 534 8158, E-mail: karinoffice@ucsd.edu

or X Li, College of Bioinformatics, Harbin Medical University, 157 Baojian Road, Harbin, 150081, China. Tel: +86 451 86695922; Fax: +86669617; E-mail: lixia@ @ hrbmu.edu.cn ${ }^{7}$ These authors contributed equally to this work.

Received 22.7.16; revised 27.2.17; accepted 06.3.17; Edited by G Melino; published online 07.4.2017
} 
TFs, including GFI1 (Growth factor independence 1) and STAT3, was significantly altered after LSMCM application (Supplementary Figure S1B and Table 1).

GFI1 is a six-zinc-finger transcription repressor belonging to the SNAG domain family. ${ }^{23}$ GFI1 has primarily been examined for its roles in different haematopoietic compartments, ${ }^{24,25}$ cell cycle regulation, ${ }^{23}$ and haematopoiesis. ${ }^{26-29}$ Outside of the haematopoietic system, GFI1 is involved in lineage decisions during intestinal epithelial cell (IEC) differentiation. ${ }^{30,31}$ Until recently, however, it is not known whether GFI1 contributes to CRC development and progression. Here, we described the establishment of a constitutively activated feed-forward inflammatory signalling circuit normally harnessed through GFI1 during CRC progression. This circuit has crucial roles in promoting CRC metastatic spread.

\section{Results}

Monocyte-derived TGF $\beta$ induces inflammation-linked CRC cell metastatic behaviours. We generated a previously established cellular model using LSMCM culture medium conditioned by LPS-stimulated monocytes (Supplementary Figure S2A). ${ }^{21,22}$ Four (HT29, LoVo, HCT116, and SW480) of the five CRC cell lines (including SW620) actively responded to LSMCM, morphologically changing into spindleshaped fibroblast-like cells (Figure 1a). Further examination revealed that LSMCM greatly induced EMT and increased cell migration and invasion in responsive cells (Figure $1 \mathrm{~b}-\mathrm{i}$ and Supplementary Figure S2B); however, SW620 cells were the least responsive to LSMCM (Figure 1j and k), in which remnant LPS had a minor effect (Supplementary Figure S2C). Moreover, the conditioned medium derived from LPS-stimulated macrophages differentiated from human peripheral blood mononuclear cells (PBMCs), or the U-937 human monocyte cell line significantly induced EMT and increased cell migration and invasion in HT29 cells (Supplementary Figure S2D-F). These supplementary models provided proof of concept on the cellular model system to study the effect of TAMs and the tumour microenvironment in vitro.

To understand how LSMCM elicited these phenotypic changes, we analysed the supernatants of LSMCMstimulated HT29 cells on 40 selected cytokines highly relevant to activated macrophages. ${ }^{32}$ The results indicated that the concentrations of TGF $\beta 1$, IL $1 a$, IFN $\gamma$, I309 (CCL1), and TNF $\beta$ were significantly decreased within the first $6 \mathrm{~h}$ of treatment and subsequently returned to levels equivalent to those present in the original LMSCM after $24 \mathrm{~h}$ of incubation, whereas GM-CSF, IL8, MCP1, PDGFBB, and sTNFR1 remained elevated for up to $24 \mathrm{~h}$ (Figure 2a). These data suggested that HT29 cells may consume or degrade certain cytokines in the medium before secreting these cytokines; these cells rapidly produced additional GM-CSF and IL8.

To identify the most important factors in LSMCM-affecting $\mathrm{CRC}$ cell behaviour, we referred to a previously identified core TF network linking IBD and CRC (Supplementary Figure S1). ${ }^{21}$ Among the 24-core TFs and their regulated network in LSMCM-stimulated HT29 cells, two genes, TGFBR2 and TLR8, were significantly upregulated (Table 1). Consistently, TGFBR2 mRNA expression increased upon
Table 1 Differential expression of varied genes at the mRNA level in HT29 cell model

\begin{tabular}{|c|c|c|c|}
\hline Gene & Fold change $^{a}$ & Gene & Fold change $^{a}$ \\
\hline GFI1 ${ }^{b}$ & -2.58 & BUB1B & 1.32 \\
\hline TGFBR2 & 2.19 & TLR8 & 2.19 \\
\hline TCF7L2 & 1.32 & RUNX $3^{b}$ & -1.14 \\
\hline REG4 & 1.09 & CD40 & -1.24 \\
\hline HDAC5 & 1.15 & CXCR4 & -1.15 \\
\hline SMAD2 & 1.21 & HDAC5 & -1.09 \\
\hline MUC2 & 1.34 & CXCL13 & -1.32 \\
\hline PTGER2 & 4.80 & CCR7 & -1.17 \\
\hline TCF7L2 ${ }^{\mathrm{b}}$ & -1.00 & SMAD2 ${ }^{b}$ & 1.44 \\
\hline RPS9 & -1.02 & SOX $10^{b}$ & 1.04 \\
\hline APC & -1.12 & TFF3 $^{\mathrm{b}}$ & 1.37 \\
\hline PTPRH & -1.20 & SMAD7 $7^{b}$ & 1.16 \\
\hline ARHGEF4 & -1.06 & ETS $1^{b}$ & 1.12 \\
\hline NAT1 & -1.18 & POU5F1B ${ }^{b}$ & -1.61 \\
\hline STAT $^{b}$ & 2.58 & FOXO1 ${ }^{b}$ & -1.41 \\
\hline AKT1 & 3.58 & HOXA4 ${ }^{b}$ & -1.30 \\
\hline ТP53І3 & 2.58 & NFYB $^{b}$ & -1.05 \\
\hline XBP1 ${ }^{b}$ & -1.60 & $\mathrm{FOXC1} 1^{\mathrm{b}}$ & -1.20 \\
\hline C5 & -1.42 & ZNF589 & 1.07 \\
\hline CCL24 & -1.06 & $\mathrm{TCF}^{\mathrm{b}}$ & 1.12 \\
\hline CHST2 & -1.20 & SREBF ${ }^{\mathrm{b}}$ & -1.13 \\
\hline IL1B & -1.16 & CEBPG ${ }^{\mathrm{b}}$ & 1.16 \\
\hline$P B X 1^{b}$ & 1.80 & NFATC $^{b}$ & -1.07 \\
\hline IL23R & 1.14 & PROM1 ${ }^{b}$ & 1.05 \\
\hline COX1 & 1.21 & $\mathrm{BACH}^{\mathrm{b}}$ & -1.26 \\
\hline TYMS & 1.64 & POU2F2 $^{b}$ & 1.02 \\
\hline
\end{tabular}

${ }^{a}$ Cells were treated with LSMCM for $24 \mathrm{~h}$. Gene expression showing at least twofold change was recognised in red as being significantly altered. Consistent results from independent real-time PCR assays were obtained. ${ }^{\mathrm{b}}$ Transcriptional factor, others are their related genes. The bold entries indicate the transcriptional factors

LSMCM addition (Supplementary Figure S3A). Furthermore, the application of anti-TGF $\beta$-neutralising antibodies prior to LMSCM significantly blunted EMT-related behavioural changes and migration/invasion in CRC cells (Figure $2 b$ and $\mathrm{C}$ and Supplementary Figure S3B, S3C). Thus, TGF $\beta$ signalling may be an important contributor to the observed changes in CRC cell behaviour.

Inflammation-linked changes in CRC cell behaviour resulting from multiple factors in the cell model system. CRC cells exhibited maximal behavioural changes after treatment for $24 \mathrm{~h}$ with LSMCM. To investigate the factors driving these changes, we examined the expression of multiple effectors in HT29 cells for up to $96 \mathrm{~h}$. The expressions of GFI1 and STAT3 were significantly altered upon LSMCM treatment, and the GFI1-associated factors PTGER2 (coding for EP2), TGFBR2, and STAT3-associated AKT1 were upregulated (Table 1). In addition, we examined ERK1/2, NF- $k$ B (p65 subunit), EMT-related Snail, Zeb1, and Twist in the expression analysis, considering their effects on inflammation and metastasis. ${ }^{33,34}$ We observed sequential changes in the expression or activities of almost all of these effectors for up to $96 \mathrm{~h}$ at the protein level (Figure $2 \mathrm{~d}$ and Supplementary Figure S3D). Two of the earliest changes were decreased GFI1 and increased ERK phosphorylation. Moreover, the expression of the GFl1-repressed gene PTGER2 expectedly increased upon LSMCM addition (Figure 2e). Other changes subsequently occurred, including the activation of STAT3, EP2, AKT, and p65 (Figure 2d); 


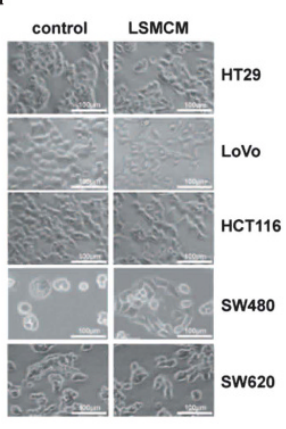

$\mathbf{b}_{\text {HT29 }}$
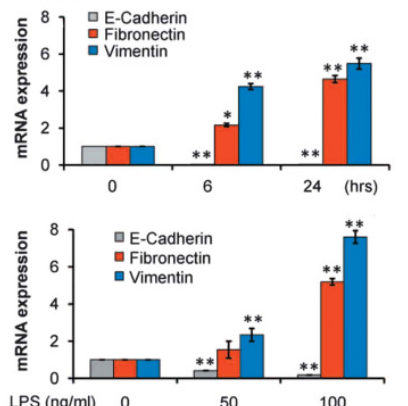

d
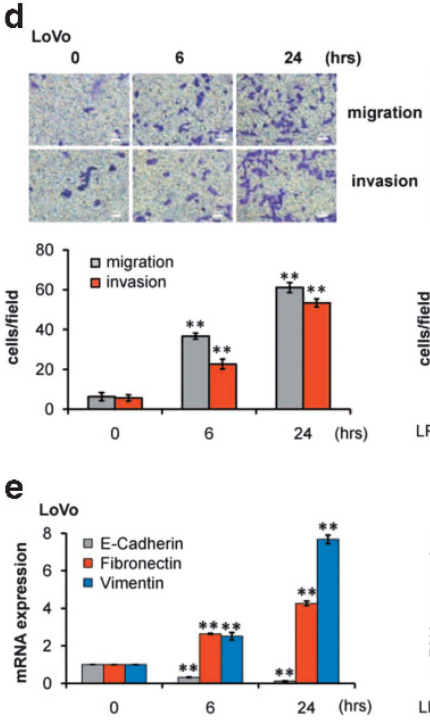

$h_{\text {sw480 }}$
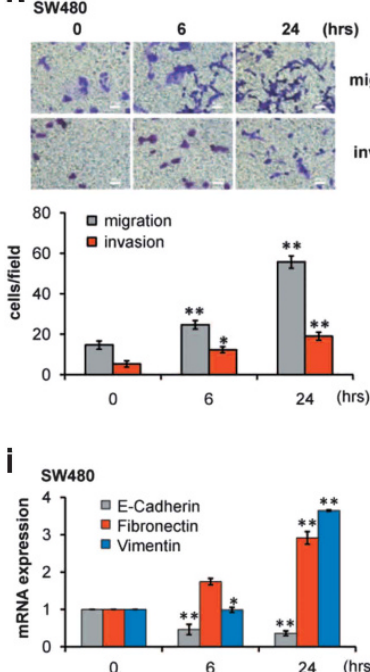
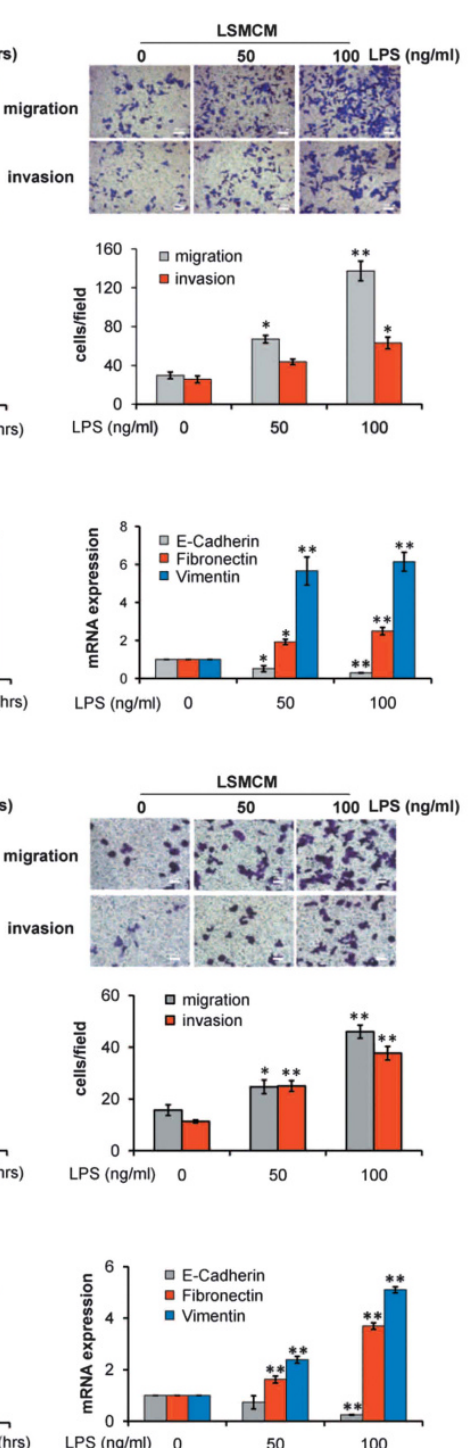

C
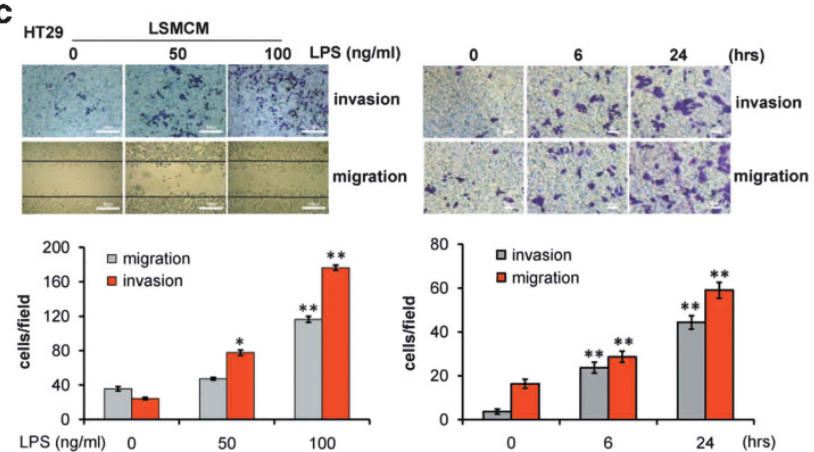

f
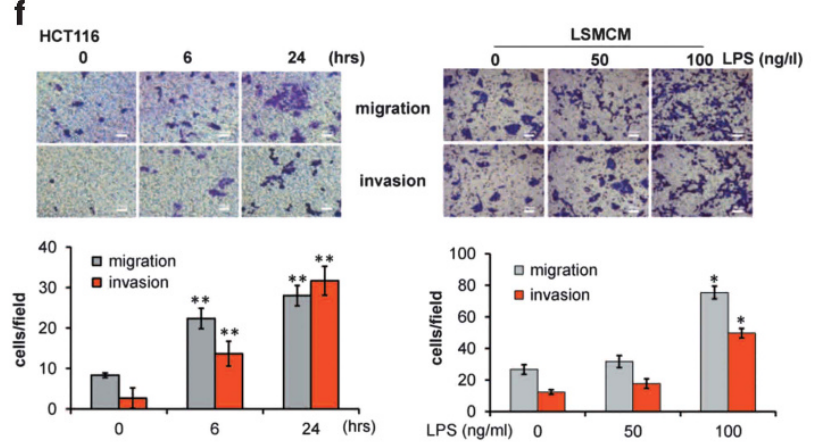

$\mathbf{g}_{\text {HCT116 }}$
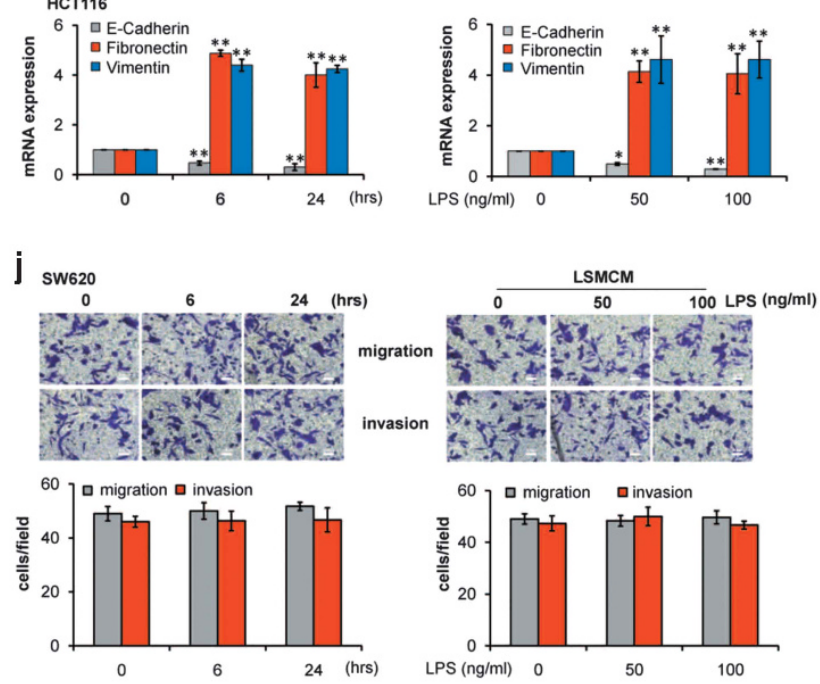

$\mathbf{K}_{\text {sw620 }}$
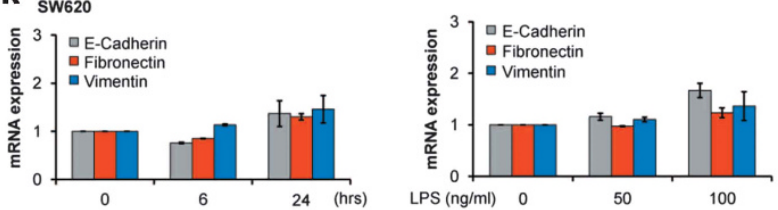

Figure 1 LSMCM increases CRC cell metastatic behaviour. (a) Culture with LSMCM induces morphology changes in HT29, LoVo, HCT116, SW480, and SW620 cells. (b) qRT-PCR of E-cadherin, Fibronectin, and Vimentin mRNA in HT29 with LSMCM for different times or prepared from supernatant of THP1 cells that were incubated with different LPS concentrations. (c) HT29 cells were treated with LSMCM for different times; or prepared from supernatant of THP1 cells that were incubated with different LPS concentrations. Cell migratory and invasive activities were measured and quantified. (d) LoVo cells were treated as in (c) and their migratory and invasive activity was measured and quantified. (e) qRT-PCR of E-cadherin, Fibronectin and Vimentin mRNA in LoVo cells treated as in (b). Results of similar experiments were exhibited for HCT116 cells, SW480 cells and SW620 cells, respectively, in (f-k). (b-k) show means \pm S.D. of three independent experiments. Statistically significant differences are indicated. ${ }^{\star} P<0.05 ;{ }^{*} P<0.01$ 


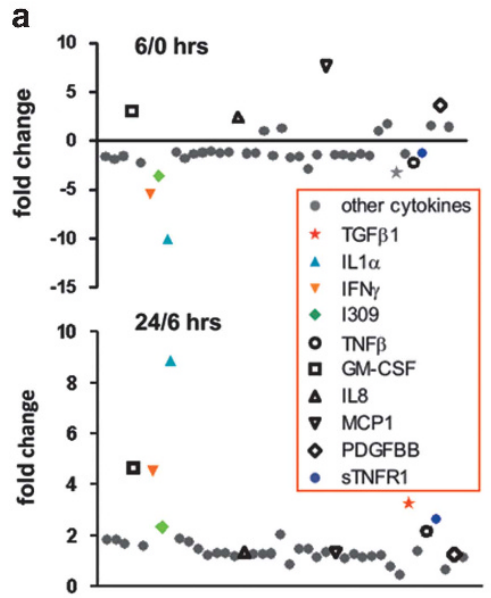

d

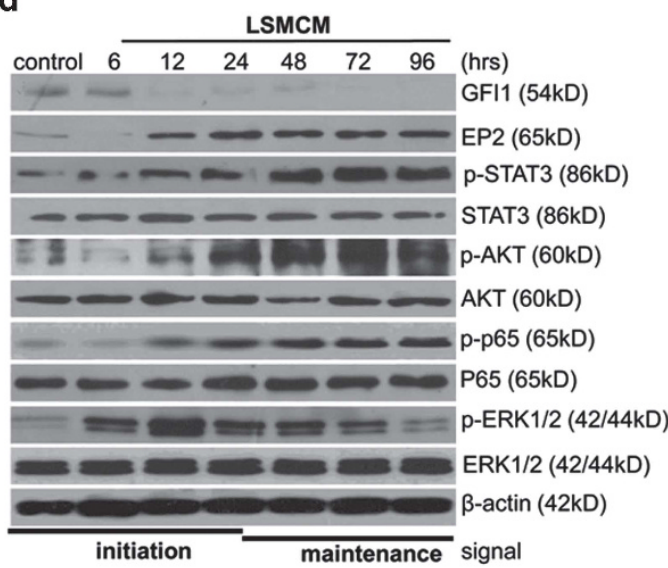

b
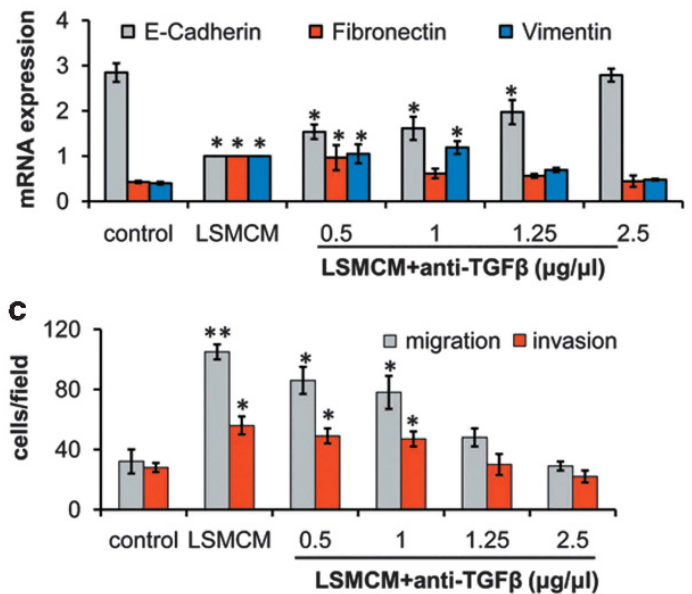

e
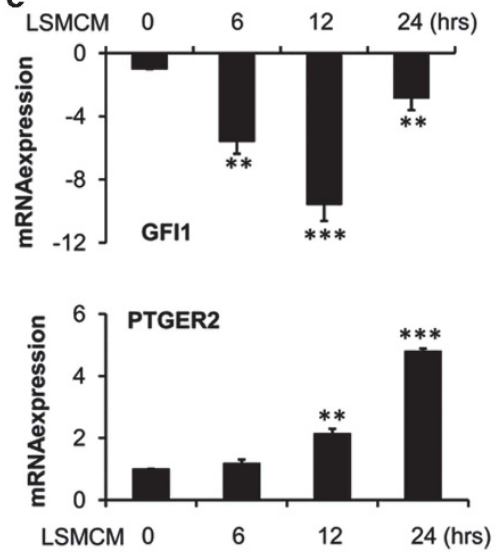

f

LSMCM+anti-TGF $\beta$ ( $\mu \mathrm{g} / \mu \mathrm{l})$

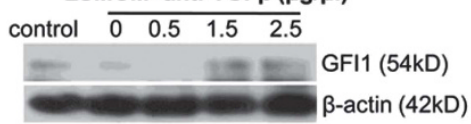

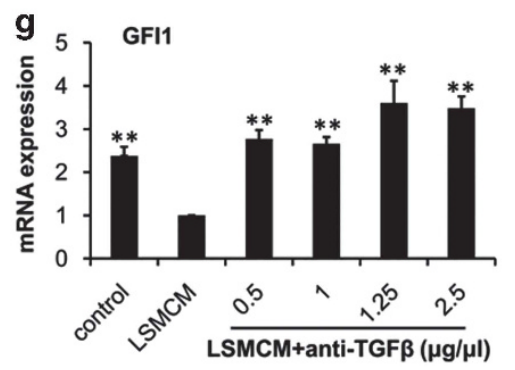

h
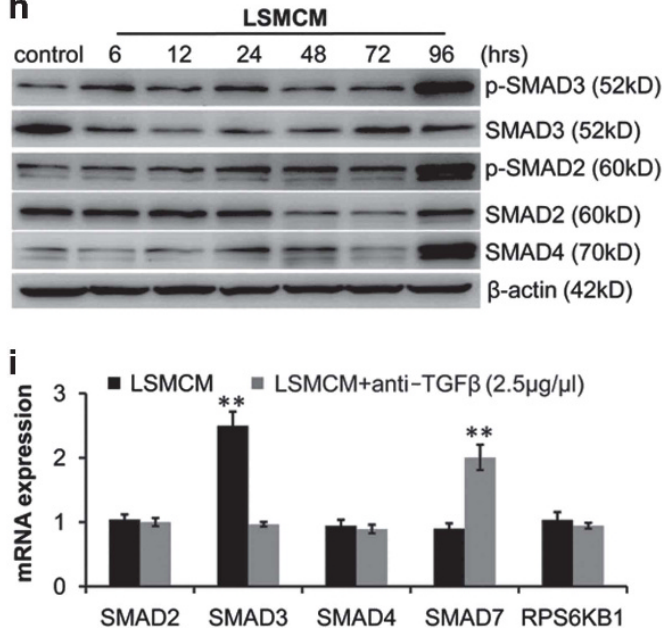

Figure 2 Monocyte-derived TGF $\beta$ downregulates GFI1 and induces EMT and cell metastatic behaviour. (a) Cytokines in culture medium from HT29 cells treated with LSMCM for 6 or $24 \mathrm{~h}$ were measured by Cytokine antibody arrays. Results shown are fold changes compared with freshly collected LSMCM. (b) qRT-PCR of E-cadherin, Fibronectin, and Vimentin mRNA in HT29 cells treated with LSMCM with/without anti-TGF $\beta$-neutralising antibodies for $24 \mathrm{~h}$. (c) Quantification of data shown in Supplementary Figure S3B, depicting the role of TGF $\beta$ in LSMCM-induced changes in cell behaviour. (d) HT29 cells were incubated with LSMCM for up to $96 \mathrm{~h}$. Whole-cell lysates were prepared at the indicated time points and analysed for expression and phosphorylation of the indicated proteins. (e) Time course of GFI1 and PTGER2 mRNA expression in HT29 cells treated with LSMCM by qRT-PCR. (f) Effect of anti-TGF $\beta$-neutralising antibodies on LSMCM-induced suppression of GFI1 expression. (g) qRT-PCR of GFI1 mRNA in HT29 cells treated with LSMCM plus indicated concentrations of anti-TGF $\beta$-neutralising antibodies. (h) HT29 cells were treated with LSMCM for up to $96 \mathrm{~h}$, and the expression or phosphorylation of SMAD2/3/4 were analysed. (i) qRT-PCR of SMAD2, SMAD3, SMAD4, SMAD7, and RPS6KB1 mRNA in HT29 cells treated with LSMCM or LSMCM plus $2.5 \mu \mathrm{g} / \mu \mathrm{l}$ anti-TGF $\beta$ neutralising antibodies. (b), (c), (e), (g), (i) show means \pm S.D. of three independent experiments. Statistically significant differences are indicated. ${ }^{\star} P<0.05 ;{ }^{* *} P<0.01 ;{ }^{* *} P<0.001$ 
increased expressions of Snail and Zeb1, but not Twist (Supplementary Figure S3D).

Significantly, the LSMCM-induced GFI1 decrease was reversed by TGF $\beta$ neutralisation in a dose-dependent manner in HT29 cells (Figure $2 \mathrm{f}$ and g). Further assays indicated that TGF $\beta$ might exert this effect via SMAD-dependent pathways. Notably, phospho-SMAD3 was significantly elevated as early as $6 \mathrm{~h}$ and remained activated for $96 \mathrm{~h}$; phospho-SMAD2 and the expression of SMAD4 were also elevated (Figure 2h). Conversely, TGF $\beta$ neutralisation reversed the LSMCMmediated SMAD3 elevation (Figure 2i). Notably, the expression of RPS6KB1, a factor in SMAD-independent pathways, was unaffected by either LSMCM or additional TGF $\beta$ neutralisation (Figure 2i). Furthermore, in the supernatant, three other cytokines, IL $1 a$, TNF $\beta$, and IFN $\gamma$, whose expression changes were similar to those of TGF $\beta$ under LSMCM treatment (Figure 2a), led to GFI1 downregulation and the activation of cellular downstream effectors to varied extents (Supplementary Figure S3E-G). Collectively, these results showed that effects of multiple factors contributed to the transformation of CRC cells under LSMCM treatment.

GFI1 is a gating regulator in the cellular transformation of CRC cells. We next examined whether decreased GFI1 expression affected the aforementioned changes in HT29 cells. Forced GFI1 expression decreased PTGER2 (gene name for EP2) mRNA (Figure 3a) but not vice versa (Figure $3 b$ ), although a potential GFI1 binding site was detected in the STAT3 promoter but not in PTGER2 (Figure 3c). Chromatin immunoprecipitation (ChIP) assays confirmed less and less GFI1 bound to the endogenous STAT3 promoter during LSMCM stimulation (Figure 3d). GFI1 expression significantly decreased phosphorylated and total STAT3 (Figure 3e). Luciferase reporter assays revealed specific binding between GFI1 and the indicated sequence (Figure 3c) in the STAT3 promoter (Figure 3f). Furthermore, STAT3 siRNA treatment moderately reduced EP2 protein expression (Figure $3 \mathrm{~g}$ ) but not its mRNA expression (Supplementary Figure S4A). Conversely, PTGER2 siRNA treatment did not affect STAT3 expression or activation by LSMCM (Figure 3h, Supplementary Figure S4B). We subsequently detected the physical interaction between STAT3 and EP2, which was further enhanced after LSMCM treatment (Figure 3i, Supplementary Figure S4C), but not transcriptional regulation of STAT3 on PTGER2 (Supplementary Figure S4D). Thus, the GFI1-STAT3-EP2 signalling cascade is activated in HT29 cells under LSMCM stimulation.

Moreover, although GFl1-expressing cells showed decreased ERK1/2 phosphorylation (Figure 3j), ERK1/2 siRNA, or U0126 (an MEK inhibitor) treatment reduced EP2 expression at the protein level (Figure 3k, Supplementary Figure S4E) but not mRNA (Supplementary Figure S4F). However, PTGER2 siRNA had no effect on ERK1/2 phosphorylation (Figure 3I). In addition, we observed physical interactions between ERK1/2 and EP2 (Figure 3m). These data suggest that, similar to STAT3, ERK1/2 activation upon GFI1 reduction contributed to increased EP2 expression. In response to LSMCM treatment, the activation of AKT and p65 was observed later than EP2 upregulation (Figure 2d). PTGER2 siRNA treatment reduced both AKT and p65 phosphorylation (Figure 3n). Furthermore, the inhibition of AKT phosphorylation using Ly294002 reduced p65 phosphorylation; RELA (coding for p65) siRNA, or PDTC (an inhibitor of NF- $K B$ activation) had only a minor effect on AKT phosphorylation (Figure 3o, Supplementary Figure S4G). These data suggest the existence of an EP2-AKT-NF-KB cascade.

GFI1 downregulation enhances the metastasis of human CRC cells. To determine whether the activation of signalling effectors affects the consequent production of cytokines, we examined expressions of 10 cytokines in HT29 cells incubated in LSMCM for $24 \mathrm{~h}$. The results showed that, except for IFN $\gamma$ (data not shown), the mRNA expression of GM-CSF, IL8, MCP1, PDGFBB, sTNFR1, TGF $\beta 1$, IL1 $a$, I309, and TNF $\beta$ significantly increased (Figure 4a). Moreover, ELISA showed a significant decrease in TGF $\beta$ production at $6 \mathrm{~h}$ and a return to basal amounts at $24 \mathrm{~h}$ after LMSCM addition (Figure 4b), consistent with previous data (Figure 2a). We next applied shRNA, siRNA or gene overexpression to GFI1, PTGER2, STAT3, or RELA in the cell model. The results showed that forced GFI1 expression suppressed all 9 cytokines at the mRNA level, but GFI1 knockdown induced the expression of these molecules; PTGER2 siRNA had only moderate inhibition effects. In comparison, gene knockdown of STAT3 or RELA had variable effects, inhibiting the expression of certain cytokines while increasing others (Figure 4c). Collectively, the most consistent effect of LSMCM incubation was the repression of GFI1, which acts as a suppressor of cytokine gene expression. The effect of decreased GFI1 may be mediated via STAT3 and ERK1/2, which stimulate EP2 expression (Figure 4d).

Moreover, GFI1 overexpression in LMSCM-stimulated HT29 cells reversed the changes in the expression of EMT markers and greatly inhibited cell migration and invasion (Figure 4e and f); conversely, GFl1 knockdown significantly enhanced cell migration \& invasion, induced EMT (Figure $4 \mathrm{~g}$ and $h$ ), and increased EP2 expression and STAT3, p65, AKT, and ERK phosphorylation (Supplementary Figure $\mathrm{S} 4 \mathrm{H}$ ). Keeping consistent, we further showed that although SW480 cells exhibited the weakest response and SW620 cells exhibited the strongest response to LSMCM stimulation, the expression of GFI1 was the highest in SW480 cells and lowest in SW620 cells among the tested CRC cells (Figure 5a and b). In parallel, forced GFI1 expression in SW620 cells significantly reduced cell migration and invasion and vice versa (Figure 5c-f). Whereas SW620 cells poorly responded to LSMCM stimulation (Figure $1 \mathrm{a}, \mathrm{j}$ and $\mathrm{k}$ ), forced GFI1 expression greatly enhanced SW620 sensitivity to LSMCM (Figure $5 \mathrm{~g}$ ). Collectively, these data indicated an essential role for GFI1 downregulation in coordinating the changes in the cell behaviour and metastatic potential of CRC cells.

GFI1/Gfi1 inhibits CRC metastasis to distal sites. We further examined GFI1 effect in vivo. GFI1 overexpression and control HT29 cells incubated with LMSCM for $24 \mathrm{~h}$ were subcutaneously (s.c.) transplanted into DKO (BALB/c$\operatorname{Rag2}^{--} \mathrm{gC}^{-1-}$ ) mice, and the s.c. tumour masses were harvested. The tumour growth rates, volume and mouse body weight were similar between the two groups of animals 
a

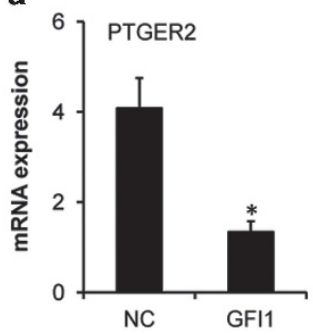

b

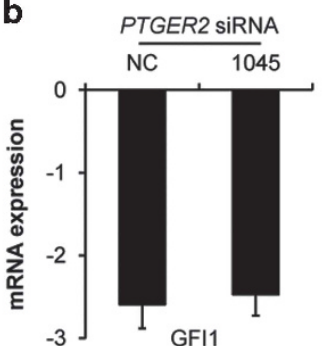

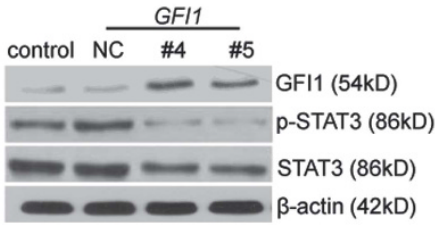

f $\perp_{\text {luciferase - }}$

GFI1 binding site on STAT3 promoter

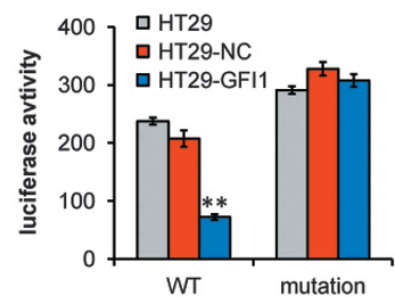

g

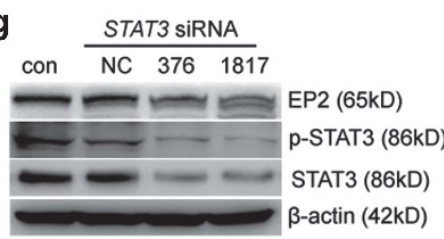

i

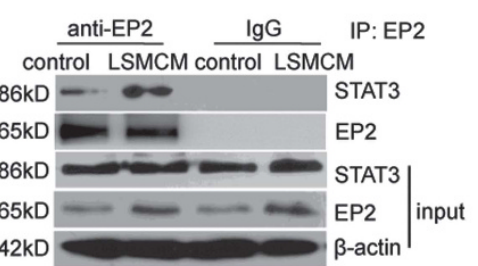

k

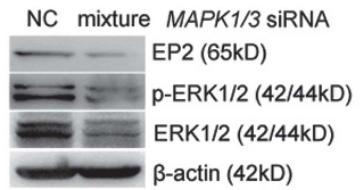

m

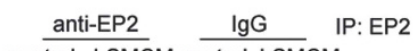
control LSMCM control LSMCM

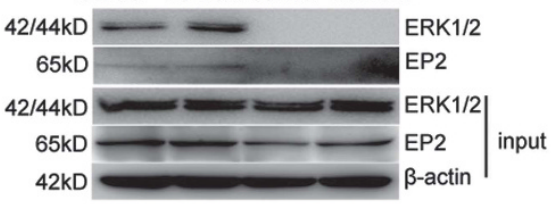

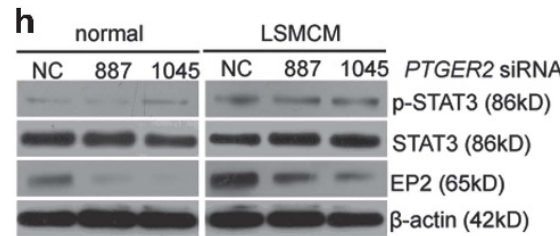

j $_{\text {control NC \#4 \#5 }}$

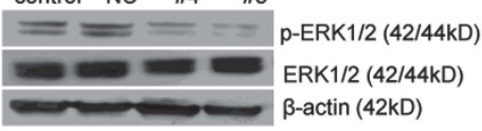

I

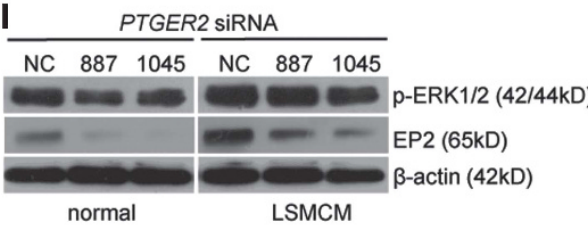

o LSMCM

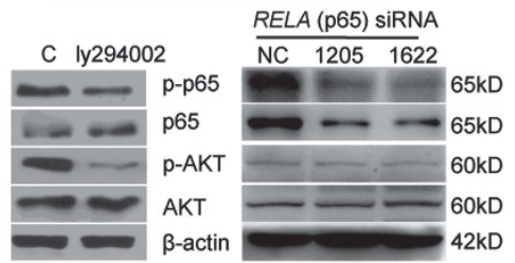

n

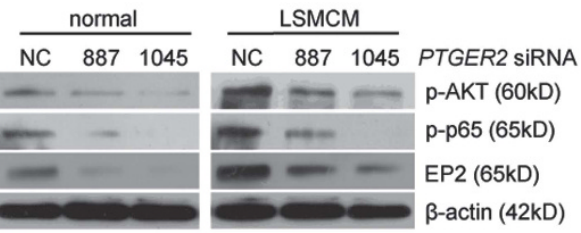


before and after tumour cell transplantation (Supplementary Figure S5A-E). Immunoblot analysis confirmed GFI1 overexpression and the decreased expression of STAT3, Snail, and Zeb1 in GFl1-positive tumours in vivo (Supplementary Figure S5F).

Next, we injected cultured GFI1-expressing (GFI1-T) and NC-T s.c. tumour cells via the tail vein (t.v.) into DKO mice (Supplementary Figure S5G). LSMCM stimulation for $24 \mathrm{~h}$ prior to tumour cell injection greatly accelerated lung metastasis in the NC-T group, reducing latency from 90 to $30 \mathrm{~d}$ compared with cells not subjected to LSMCM stimulation (data not shown). Moreover, significantly more lung metastases were observed in the NC-T than GFI1-T group at $30 \mathrm{~d}$ (Supplementary Figure S5H, I). Furthermore, at $60 \mathrm{~d}$, all eight NC-T mice and only one of the eight GFI1-T mice showed lung metastases, whereas three out of eight NC-T and no GFI1-T mice showed secondary metastasis to the liver, with significantly larger metastases in the lungs of NC-T mice (Supplementary Figure S6A-F). In addition, NC-T mice exhibited more weight loss compared with GFI1-T mice (Supplementary Figure S6G). H\&E staining of the lung biopsies showed that the NC-T mice had more macroscopic tumours than GFI1-T mice; and NC-T liver metastases were also large (Supplementary Figure S6B, E).

To further investigate the role of murine Gfi1 in CRC cell metastasis in immune competent mice, we constructed MC38Gfi1 and MC38-con cell lines using CRISPR/Cas9 technology. Forced Gfi1 activation in metastatic MC38 CRC cells reduced the rates of cell migration and invasion, diminished the expressions of EP2 and STAT3, and attenuated STAT3, AKT, and p65 phosphorylation (Figure $6 \mathrm{a}$ and b). We next intrasplenically (i.s.) injected these cells into syngeneic C57BL/6 mice and subsequently examined liver metastases and disease progression. Gfi1 overexpression greatly reduced tumour metastatic incidence (Supplementary Figure $\mathrm{S} 6 \mathrm{H}$ ), liver metastases sizes and body weight in age-matched groups (Figure 6c-f). In addition, MC38-Gfi1 mice survived much longer than the control mice (Figure $6 \mathrm{~g}$ ).

GFI1 downregulation increased the metastatic ability of CRC cells in vivo. HT29 cells harbouring GFl1 gene knockdown by shRNA or control plasmid were s.c. transplanted into nude mice and harvested at $20 \mathrm{~d}$. The results showed no significant differences between the two groups of mice in animal body weight, tumour formation rate, and tumour weight and volume (Supplementary Figure S7A-E), although shGFI1 tumours seemed smaller than the controls (Supplementary Figure S7C, D). Next, we injected these two groups of cells via the t.v. into the mice. At $40 \mathrm{~d}$ after injection, all of the lungs from the shGFI1 mice and none of the lungs from control mice developed pronounced lung metastases (Supplementary Figure S7F, G). GFl1 knockdown had a minor effect on the body weight of the mice; H\&E staining revealed that the lungs from shGFl1 mice showed aggregated $\mathrm{CRC}$ cells around the blood vessels to form larger metastases (Supplementary Figure S7H, I).

To determine whether GFI1 downregulation correlated with CRC metastatic progression in humans, we analysed a TCGA data set including 155 patient biopsies from primary tumour sites. The results indicated that the primary tumours from patients with metastatic CRC (M1) expressed significantly less GFI1 than those from patients who did not progress to metastatic disease (M0) (Figure 6h). Collectively, these data strongly suggest that GFI1 downregulation promotes CRC metastasis to distant organs.

Loss of GFI1 in advanced human CRC samples. To further relate GFI1 expression with CRC metastasis, we examined a series of human biopsies, including normal colon tissues $(n=10)$, cancer adjacent normal colonic tissue $(n=10)$, precancerous colon lesions $(n=5$ adenomatous and $n=5$ polyp tissues), CRC $(n=23)$ and CRC metastatic lesions $(n=23)$ using IHC (Figure 7a). The loss of GFI1 expression was primarily observed in advanced CRC (stage IIB and higher) and metastases compared with normal and lower stage tissues, respectively (Figure $7 \mathrm{~b}$ and $\mathrm{c}$ ). Decreased GFI1 expression was initially observed at stage IIB and further decreased at stage III (Figure 7a), suggesting that GFI1 dowregulation likely precedes metastatic spread. In addition, in the same set of human samples, the markedly increased expression of STAT3 was observed in CRC compared with normal biopsies (Supplementary Figure S8A, B), although the expression was similar between earlyand late-stage tumour samples (Supplementary Figure S8C). Moreover, a negative correlation between GFI1 and STAT3 expression at the protein level was observed across all categorised sample sets, and significantly correlated expression was only observed in normal colon specimens and metastases (Supplementary Figure S8D). These data

Figure 3 GFI1 is a gating regulator that controls CRC cell metastatic activity. (a) qRT-PCR of PTGER2 mRNA in HT29 cells transfected with GFI1-encoding or control plasmid. (b) qRT-PCR of GFI1 mRNA in HT29 cells treated with PTGER2 siRNA or NC. (c) Analysis of GFI1 binding sites in PTGER2 or STAT3 promoters. (d) ChIP assays of GFI1 recruitment to the STAT3 promoter in HT29 cells incubated with LSMCM for up to $96 \mathrm{~h}$. The data are presented as enrichment of precipitated DNA from chromatin incubated with an anti-GFI1 antibody versus IgG. (e) GFI1 and STAT3 expression and phosphorylation in HT29 cell transfected with control or GFI1-encoding plasmids. (f) Luciferase assays measuring GFI1 -repressive activity in HT29 cells transfected with STAT3 promoter (WT) or (mutant)-luc plasmid. (g) EP2 and STAT3 protein expression and phosphorylation in HT29 cells treated with control or STAT3 siRNA. (h) STAT3 expression and phosphorylation in HT29 cells treated with PTGER2 or control siRNA. (i) Co-IP assays of STAT3 binding to EP2 in HT29 cells treated with or without LSMCM. Data are presented as enrichment of precipitated protein from whole-cell lysates immunoprecipitation with an anti-EP2 antibody or non-specific lgG. (j) Total and phosphorylated ERK1/2 levels in HT29 cells transfected with the GFl1-encoding plasmid or control. (k) EP2, ERK1/2, and phosphor-ERK1/2 expression in HT29 cells pretreated with MAPK1/3 siRNA or control. (I) ERK1/2 phosphorylation in HT29 cells treated with PTGER2 siRNA or control. (m) Co-IP assays of ERK1/2 binding to EP2 in HT29 cells treated with or without LSMCM. (n) AKT and p65 phosphorylation in HT29 cells transfected with control (NC) or PTGER2 siRNA with or without LSMCM. (0) AKT and p65 phosphorylation in HT29 cells pretreated with or without $20 \mu \mathrm{M}$ PI3K inhibitor (Ly294002) or RELA siRNA for $12 \mathrm{~h}$, followed by treatment with LSMCM or LSMCM plus respective inhibitors or siRNA for $24 \mathrm{~h}$. Results in (a), (b), and (f) are shown as means \pm S.D. of three independent experiments. Statistically significant differences are indicated. ${ }^{*} P<0.05 ;{ }^{* *} P<0.01$ 
a

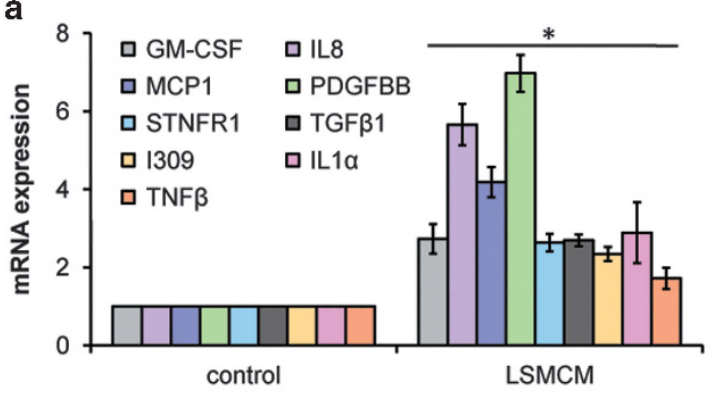

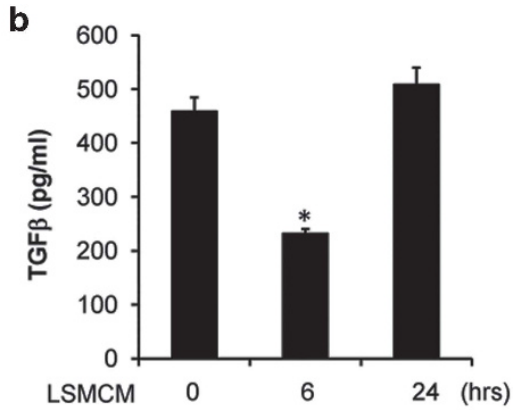

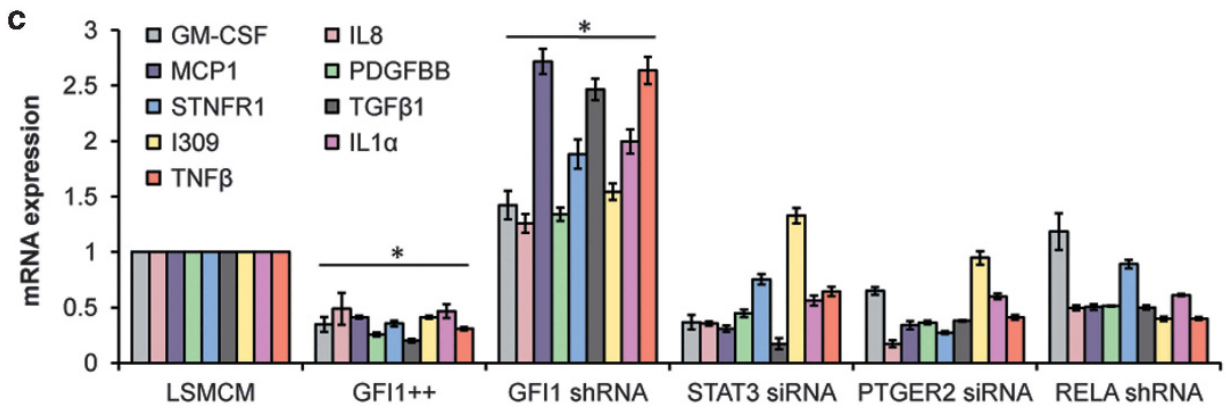

d
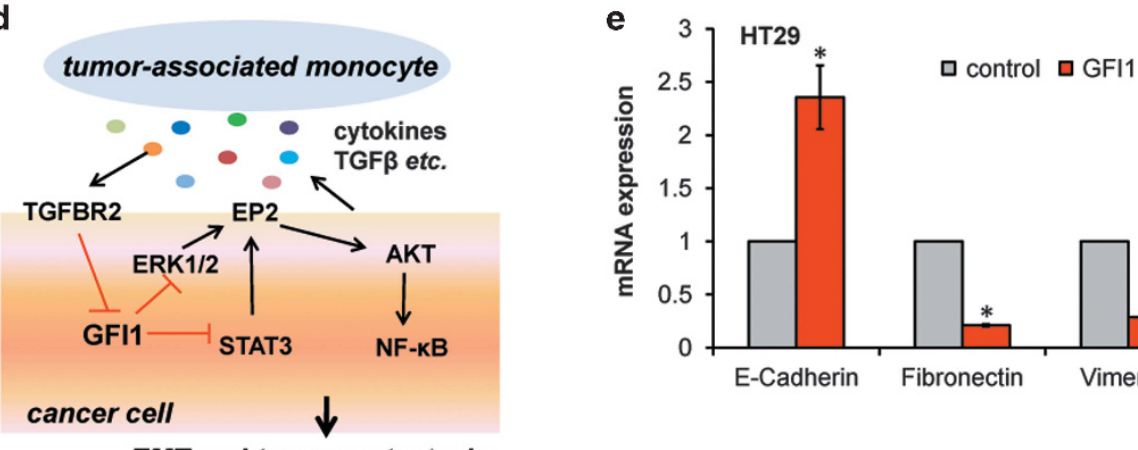

EMT and tumor metastasis

f
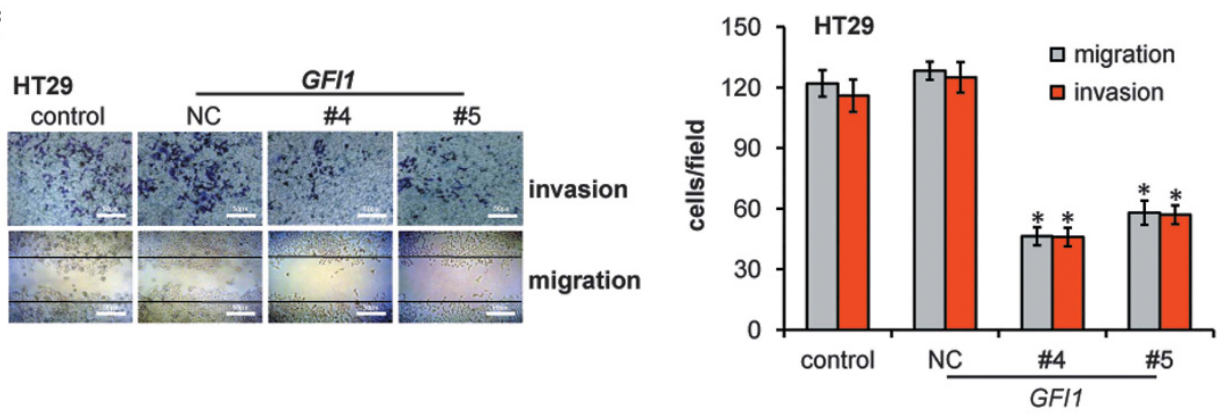

$g_{\text {HT29 }}$
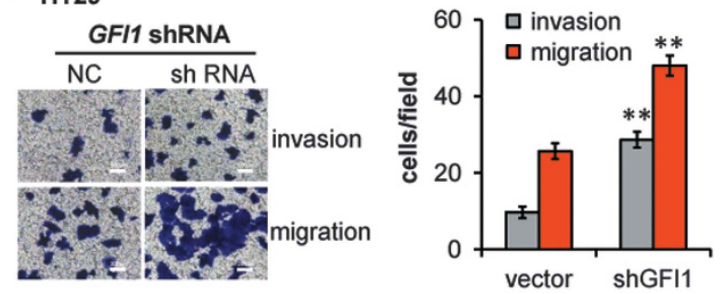

h

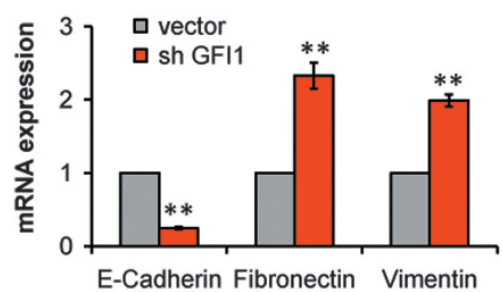


a

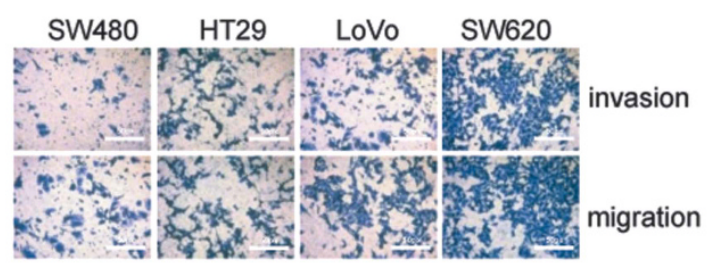

b

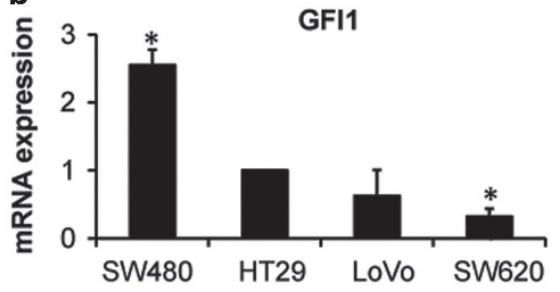

C

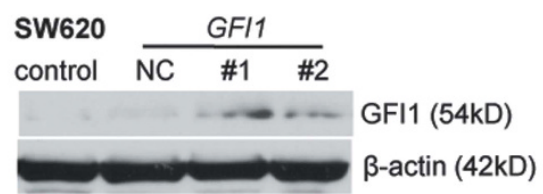

e
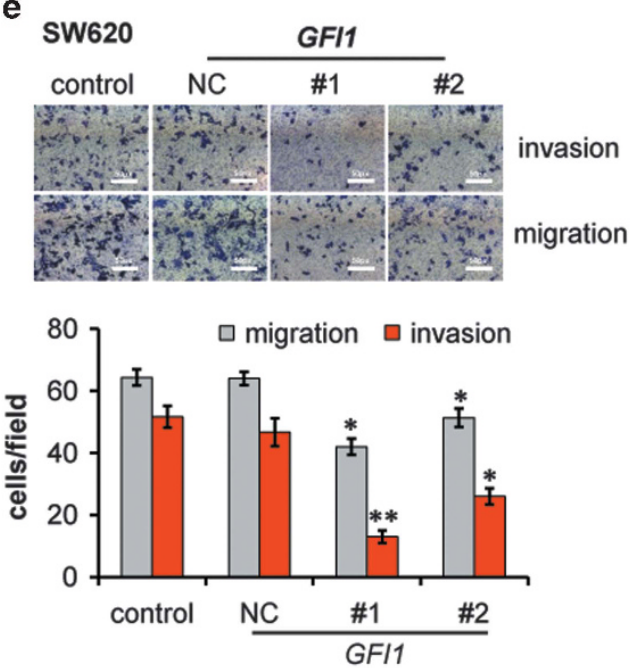

g sw620

control LSMCM

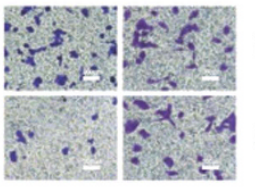

invasion

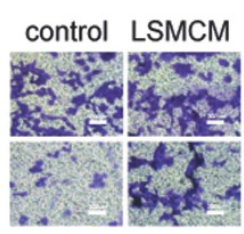

migration vector

\section{GFI1}

$$
\text { (2) }
$$

Figure 5 GFI1 controls invasive and metastatic behaviour of CRC cells. (a) Invasive and migratory activity of different CRC cell lines (SW480, HT29, LoVo, SW620). (b) qRTPCR of GFI1 mRNA in three other human CRC cells shown relative to GFI1 mRNA content of HT29 cells. (c) GFI1 protein expression in SW620 cells transfected with GFl1-encoding plasmid or control. (d) GFI1 protein expression in SW480 cells transfected with GFI1 shRNA plasmid or control. (e) Migratory and invasive behaviour of SW620 cells transfected with negative control or GFI1-encoding plasmids or control. (f) Migratory and invasive behaviour of SW480 cells transfected with negative control or GFI1 shRNA plasmids or control. (g) Migratory and invasive behaviour of SW620 cells transfected with negative control or GFl1-encoding plasmids upon LSMCM stimuli. (b), (e-g) are shown as means \pm S.D. of three independent experiments. Statistically significant differences are indicated. ${ }^{*} P<0.05 ;{ }^{* *} P<0.01$

tS.D. of three independent experments. Statistically significant differences are indicated. " $P<0.05 ; * x<0.01$

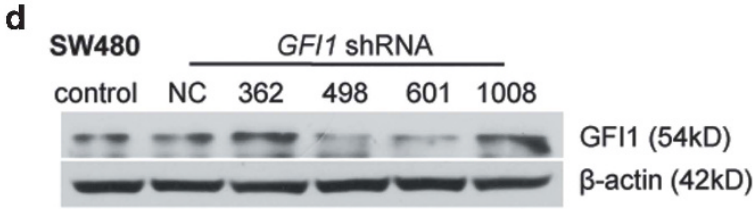

f SW480 GFI1 shRNA
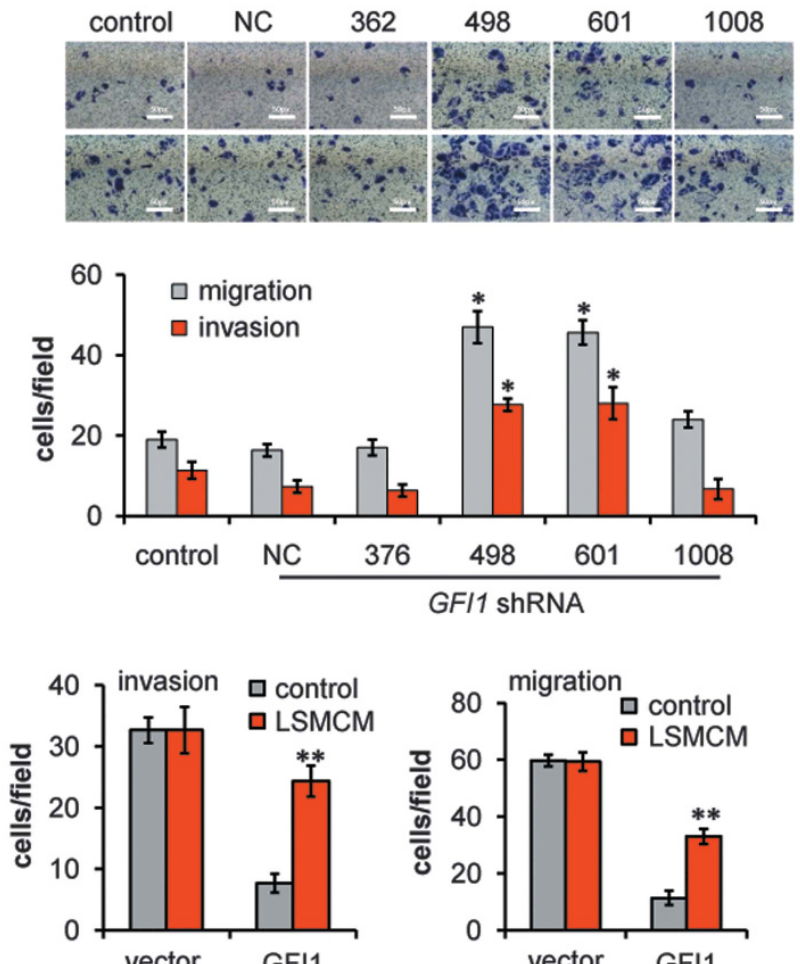

\footnotetext{
Figure 4 GFI1 controls an inflammatory signalling circuit that enhances invasive and migratory behaviour of human CRC Cells. (a) qRT-PCR of indicated cytokine mRNA in HT29 cells incubated with control medium or LSMCM for $24 \mathrm{~h}$. (b) TGF $\beta$ concentrations by ELISA assays in supernatants from HT29 cells that were treated with LSMCM for the indicated periods. (c) qRT-PCR of shown cytokine mRNA in HT29 cells treated with LSMCM or LSMCM with the indicated shRNAs, siRNAs, or GFI1-expressing plasmids. (d) Schematic overview of the inflammation and TGF $\beta$-induced regulatory circuit that controls CRC cell metastatic behaviour. (e) qRT-PCR of E-cadherin, Fibronectin, and Vimentin mRNA in HT29 cells transfected with GFI1-encoding plasmid or control. (f) Regulation of HT29 invasive and migratory behaviour by ectopically expressed GFI1. (g) Regulation of HT29 invasive and migratory behaviour by knocking down of GFI1 expression. (h) qRT-PCR of E-cadherin, Fibronectin and Vimentin mRNA in HT29 cells transfected with GFI1 shRNA or control. $(\mathbf{a}-\mathbf{c}),(\mathbf{e}-\mathbf{h})$ are shown as means \pm S.D. of three independent experiments. Statistically significant differences are indicated. ${ }^{*} P<0.05$; ${ }^{* *} P<0.01$
} 

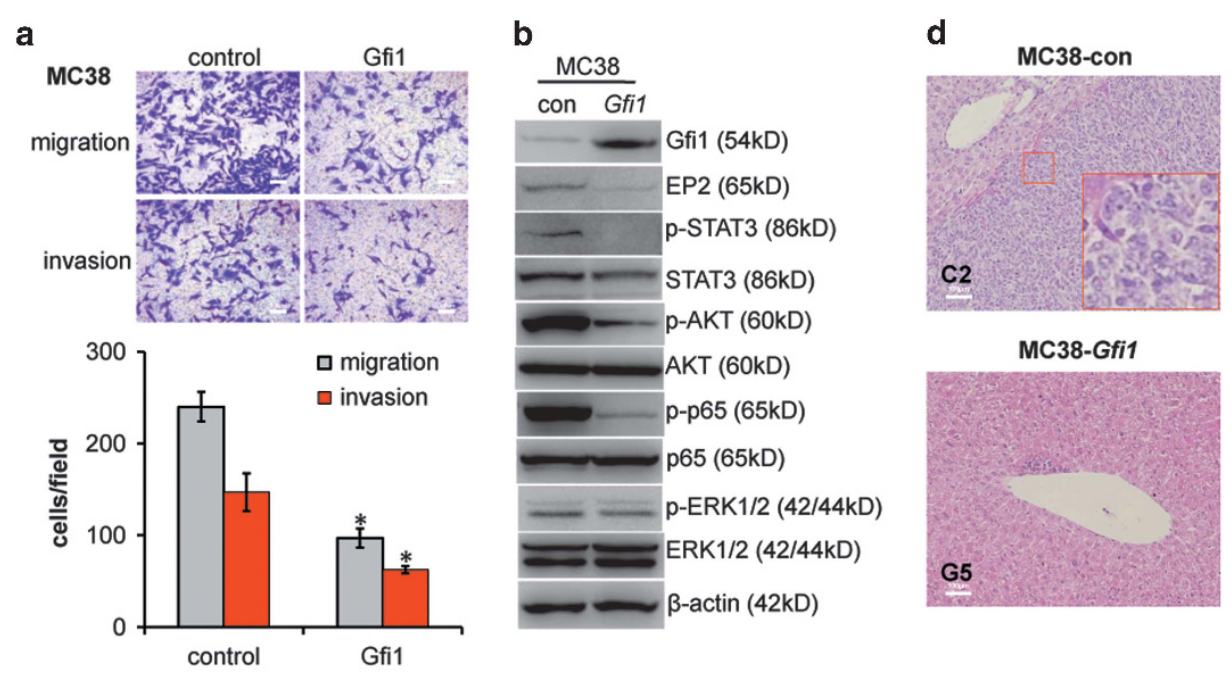

c
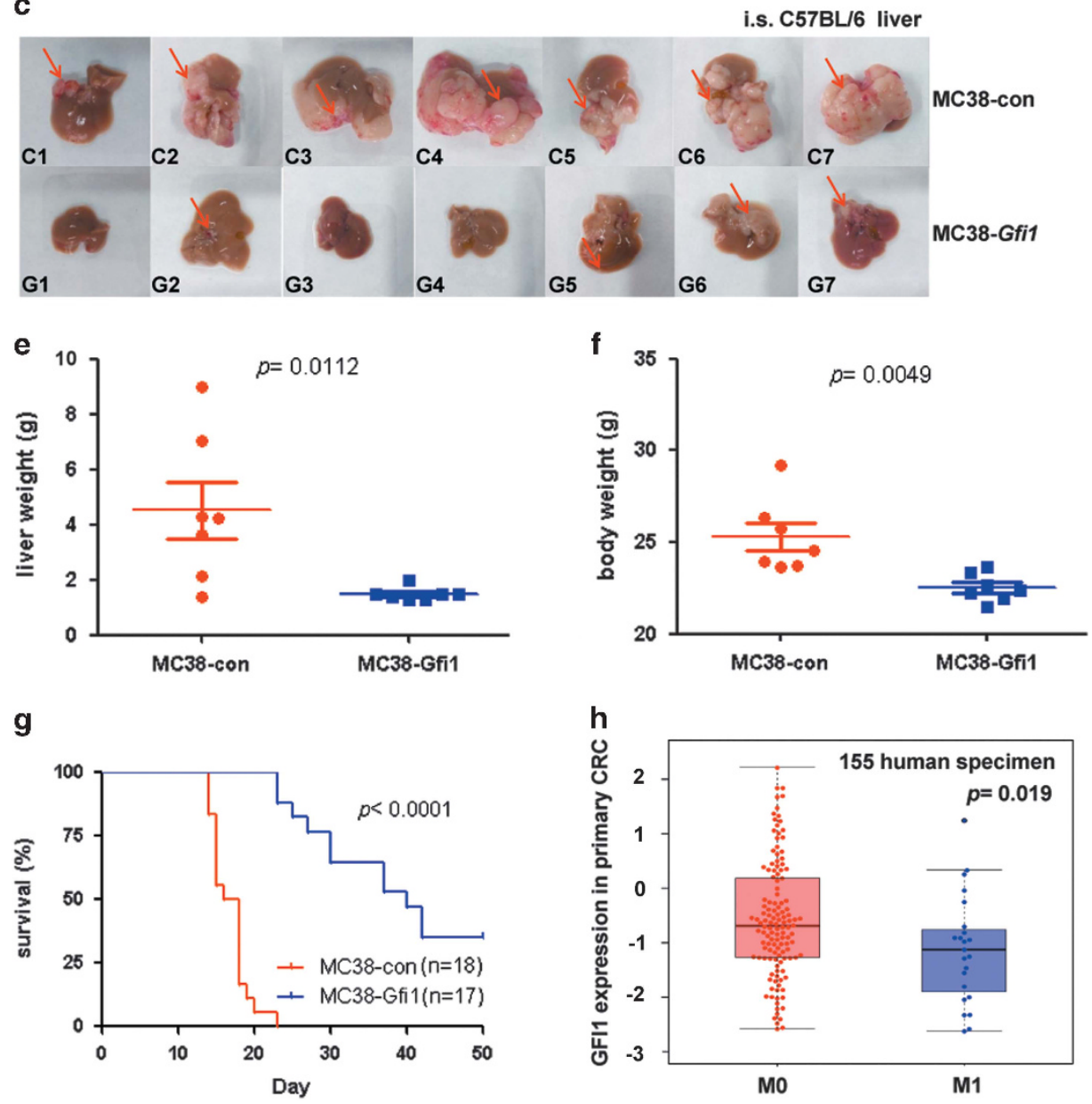

Figure 6 Gfi1 inhibits MC38 metastasis to liver. (a) Migratory and invasive activity of MC38 cells transfected with control or Gfi1-activation plasmids. (b) Immunoblot analysis of MC38-con and MC38-Gfi1 cells demonstrating effects of Gfi1 on indicated signalling proteins. (c) Liver metastases in mice injected intrasplenicly (i.s.) with MC38-con or MC38-Gfi1 cells. Arrows pointed to metastases in the liver. (d) Representative H\&E-stained sections of the livers of mice injected with MC38-Gfi1 or MC38-con cells. (e) Weights of livers in mice injected with MC38-Gfi1 or MC38-con cells 16 days after i.s. injection. (f) Weight of mice injected with MC38-Gfi1 or MC38-con cells 16 days after i.s. injection. (g) Kaplan-Meier survival curve in respective MC38-Gfi1 and -con mice, log-rank test, $P<0.0001$. (h) GFI1 expression levels in the primary tumour of human CRC in patients who did (M1) or did not (M0) develop distal metastases in a TCGA data set 
suggest that GFI1 downregulation may be highly correlated with increased STAT3 expression in CRC human samples.

To confirm the role of GFI1 in an even larger number of clinical samples, we examined the public databases of colon cancer data sets, including CRC data from TCGA, GSE17538, GSE41258, and GSE14333, comprising a total of 918 clinical samples. Notably, a significant decrease in GFI1 expression was observed in advanced CRC relative to early-stage tumours (Figure 7d). To evaluate the clinical prognosis value of GFl1 expression, we used another set of CRC data containing 177 samples harbouring relapse-free survival time (GSE39582). By stratifying cancer patients according to GFI1 mRNA expression (median), we observed that lower GFI1 mRNA expression was associated with decreased patient survival (Figure 7e). Interestingly, a significant GFI1 loss was also observed in adenomas and polyps compared with normal tissues (Figure 7f), suggesting that this loss might be an early event in colon carcinogenesis that needs to exceed a certain threshold to enable cancer cells to acquire metastatic properties.

\section{Discussion}

Cancer metastasis is a multi-step process relying on tumourstroma interactions. Inflammation greatly contributes to CRC development and progression. ${ }^{20,35,36}$ In the present study, we identified an inflammatory environment-mediated transcriptional programme that controls the metastatic potential of CRC through GFI1, a transcriptional repressor. Curiously, a key cytokine responsible for GFI1 downregulation is TGF $\beta$. Although in early CRC cells and premalignant lesions, the TGF $\beta$ signalling pathway has tumour-suppressive activities, ${ }^{37-39}$ the pro-metastatic activity of this signalling pathway is observed in more advanced cancer. ${ }^{40,41}$ These results suggest that tumour stromal cytokines may accomplish pro-metastatic activity through GFI1. Importantly, the analysis of human clinical specimens confirmed that GFI1 downregulation correlated with increased $\mathrm{CRC}$ metastasis.

Previously, GFI1 demonstrated importance in the lineage decision process during IEC differentiation, ${ }^{30,31}$ but the results of the present study are the first to implicate GFI1 as a negative regulator of $\mathrm{CRC}$ metastasis. GFI1 downregulation during the metastatic progression of CRC may reflect increased TGF $\beta 1$ expression in TGF $\beta$ R- and SMAD2/3-expressing CRC cells. ${ }^{42}$ In addition, using a cell model of inflammation-driven metastasis, we verified that other cytokines, such as IL 1 a, TNF $\beta$ or IFN $\gamma$ in the tumour microenvironment also contributed to GFI1 decrease, thereby activating CRC cell metastatic behaviours; yet the effect of the cytokine combination or other factors needs further verification. Consistently, some of these cytokines, or conditioned medium from TAMs, were implicated in EMT-like processes and promoting metastatic behaviours in CRC cells. ${ }^{43-47}$ Moreover, NF- $\kappa$ B and/or STAT3 signalling and the feed-forward activation circuit in $\mathrm{CRC}$ cells may support metastasis to remote organs. ${ }^{48-50}$

STAT3 has been demonstrated as an important player in inflammation-associated CRC progression. ${ }^{15,51,52}$ Our data highlight STAT3 as a core TF in the inflammation-mediated TF network that controls CRC metastasis and showed that GFI1 expression inhibits STAT3 activation. Previous studies showed that GFI1 enhanced STAT3 activation through interactions with the STAT3 inhibitor PIAS3. ${ }^{29}$ In contrast, the results of the present study showed that although GFI1 controlled STAT3 transcription through binding to its promoter, GFI1 downregulation triggered via LMSCM abrogated the effect, resulting in STAT3 activation. This variation suggests the operation of a context-dependent regulatory circuit. Consistent with other data, ${ }^{41,53-55}$ we verified that EP2 signalling activation was highly relevant to inflammation-associated CRC progression.

It has been suggested that disseminated cancer cells are selected via stroma-tumour interactions before adapting to new microenvironmental conditions and giving rise to a metastatic clone. ${ }^{38,56}$ There is a debate as to whether this selection occurs within or outside the primary tumour. ${ }^{57} \mathrm{We}$ observed that once GFI1 downregulation within CRC cells reaches a certain threshold, CRC cells become competent for metastatic spread as a result of the long-term activation of a regulatory circuit that is normally repressed by GFI1. The ectopic overexpression of GFI1/Gfi1 impaired the function of this signalling circuit and inhibited the metastatic activity of $\mathrm{CRC}$ cells, and vice versa. Although we observed that GFI1 expression is lost in human metastatic $\mathrm{CRC}$ and confirmed the ability of GFI1 to suppress metastatic spread, the CRC metastasis process is complex and likely to involve additional regulation. ${ }^{20,58}$ For example, despite a strongly reverse relationship between GFI1 and STAT3 expression in normal human colorectal tissue samples, such a relationship was less pronounced in CRC samples (Supplementary Fig S8D and data not shown). As a gating regulator of CRC metastasis, GFI1 downregulation may elicit further feedback and/or network regulations on its downstream effectors, such as STAT3, besides other layers of disease complexity (Supplementary Figure S6I). Thus far, the dynamics of cellular adaptation resulting from genetic/epigenetic changes or phenotypic plasticity remain poorly understood in patients with advanced cancer. ${ }^{59}$

In summary, these findings elucidate a new mechanism contributing to the acquisition of metastatic potential during $\mathrm{CRC}$ progression. Therapeutic interventions that restore GFI1 expression may be suitable for the treatment of metastatic $\mathrm{CRC}$, a condition that conveys high rates of mortality.

\section{Materials and Methods}

Cell culture, transfection, and treatment. THP1, U-937, HT29, LoVo, SW480, and SW620 cells from ATCC and MC38 cells granted from Dr. Shoshana Yakar were cultured at $37{ }^{\circ} \mathrm{C}$ and $5 \% \mathrm{CO}_{2}$ in Dulbecco's modified Eagle's medium or RPMI 1640 medium (Hyclone, Foster City, CA, USA) supplemented with $10 \%$ fetal bovine serum (FBS). Human cells were transfected using lipofectamine (Invitrogen, Grand Island, NY, USA). LSMCM were prepared from the supernatants of human THP1 cells mock stimulated or stimulated with Salmonella enteritidisderived LPS (Sigma-Aldrich, St Louis, MO, USA) for $6 \mathrm{~h}$. THP1 cells subsequently were centrifuged, and the supernatant was filtrated to eliminate any remaining cells. PBMC were isolated from human blood using lymphocyte separation solution, and then were induced into macrophage via IL4 and IL10 stimulation. U-937 cells also pretreated as PBMC. LSM $\varphi$ M were prepared like LSMCM using macrophages derived from PBMC or U-937 cells. CRC cells then were cultivated in the presence of regular medium or half $\mathrm{LSMCM}$ or $\mathrm{LSM} \varphi \mathrm{M}$ and half regular medium. Where indicated, cells were treated with anti-TGF $\beta$ neutralising antibody (Raybiotech, Norcross, GA, USA), $10 \mu \mathrm{M}$ of U0126, $20 \mu \mathrm{M}$ of Ly294002 or $10 \mu \mathrm{M}$ of PDTC (Sigma-Aldrich) for the indicated times. 
a normal adenoma (2)
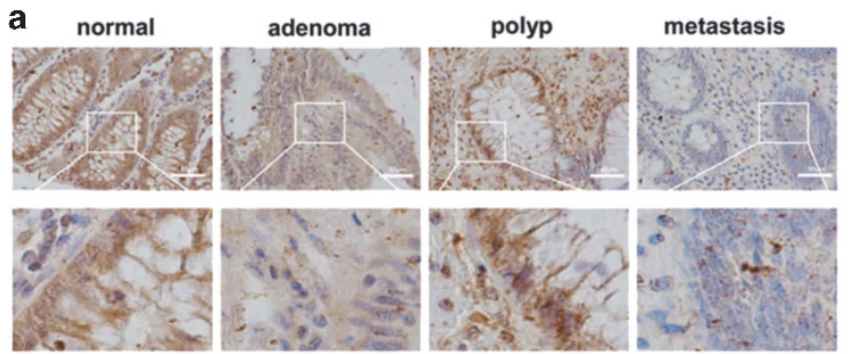

76 samples

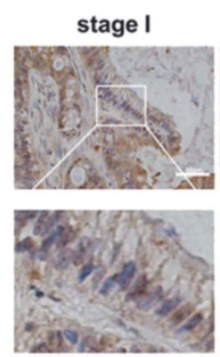

stage IIA

stage IIB

stage III

stage IV
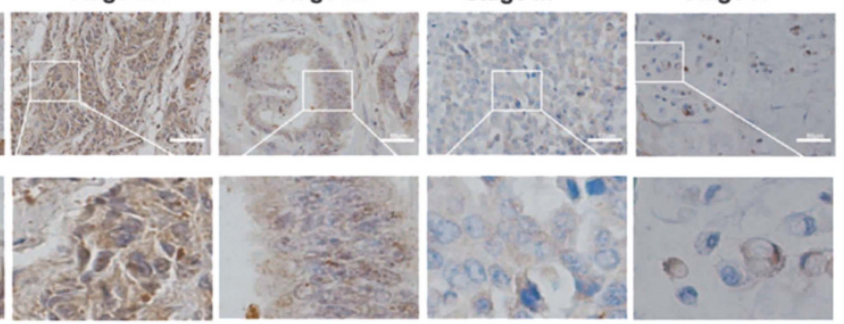

b
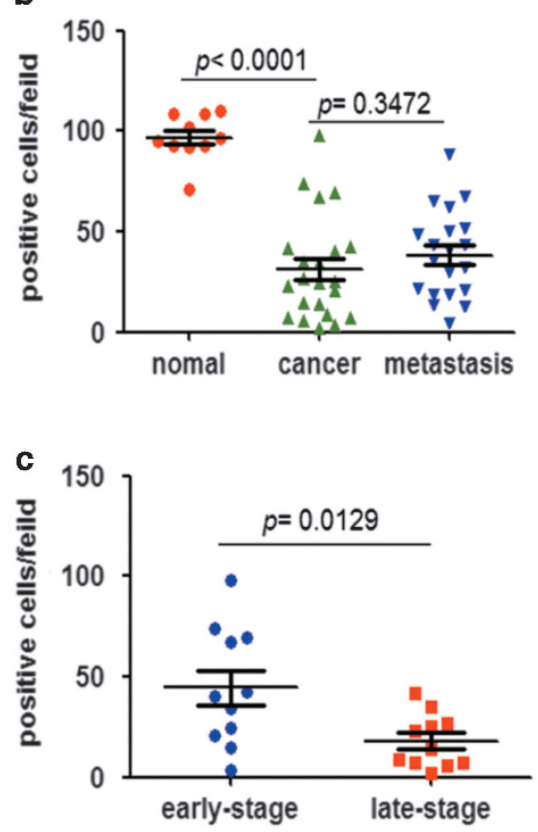

e

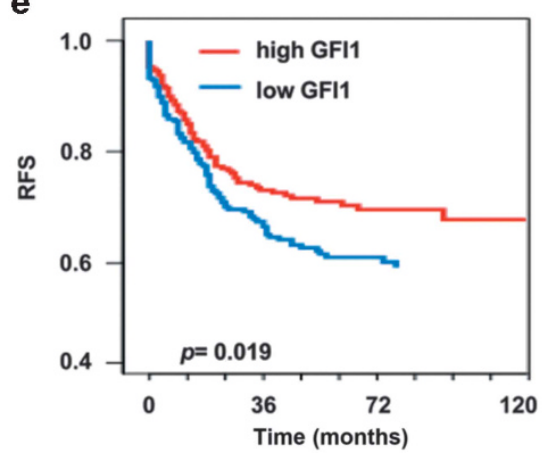

d
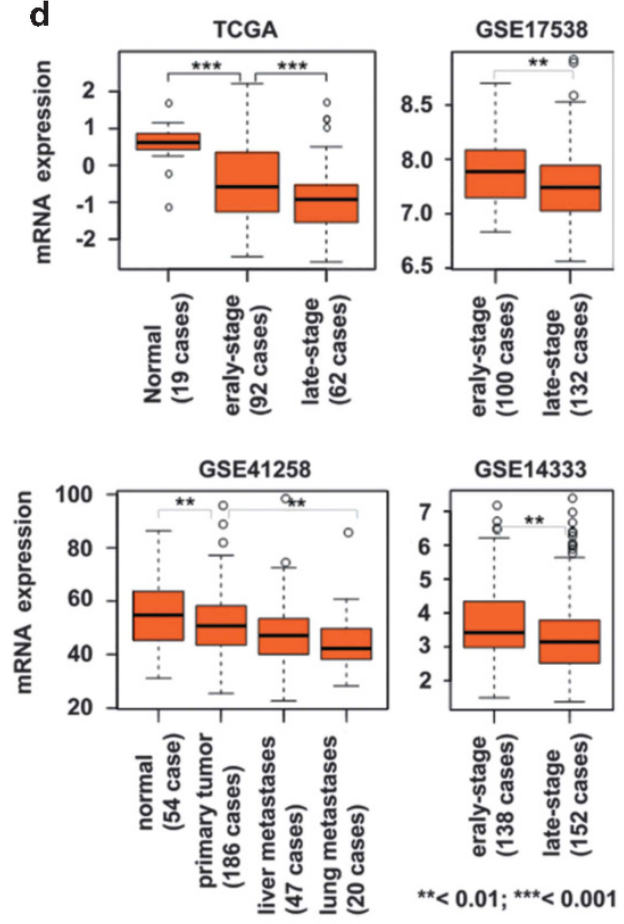

f

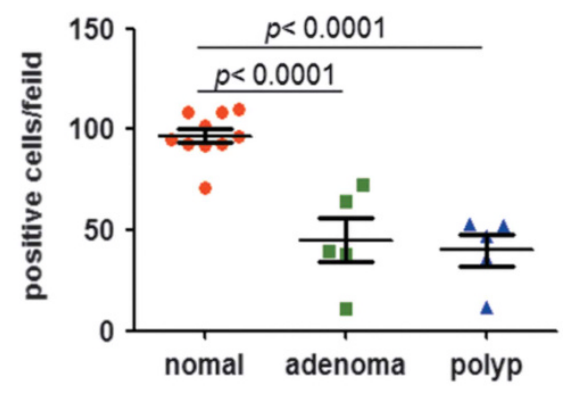


Figure 7 Loss of GFI1 in Advanced Human CRC Samples. (a) Immunohistochemical analysis of GFI1 expression in normal, cancer, metastatic nodules, adenoma, and polyp colon tissues in a total of 76 human samples. (b) Number of GFI1 expression positive cells in human normal, CRC, and metastatic tissues (four sections evaluated per sample). (c) Number of GFI1 expression positive cells in human early-stage (I and II) CRC and late-stage (III and IV) CRC (four sections evaluated per sample). (d) GFI1 expression levels in normal colon and different tumour stages from TCGA, GSE17538, GSE41258, and GSE14333 data sets. (e) Relapse-free survival of CRC patients with relatively high and low GFI1 mRNA expression. (f) Number of GFl1-expressing cells in human normal, and pre-cancer tissues including adenoma, and polyp tissues (four sections evaluated per sample)

Construction of MC38-Gfi1 cells with CRISPR activation plasmids. To generate MC38-Gfi1 and -con cells, we used CRISPR Gfi1-activation plasmid (sc-437272) and control CRISPR/Cas9 plasmid (sc-418922, Santa Cruz Ltd., Dallas, CA, USA). Gfi1 CRISPR Activation Plasmid is a synergistic activation mediator transcription activation system designed to specifically upregulate gene expression according to manufacturer's instructions (Santa Cruz Ltd.). In brief, we infected MC38 cells with three plasmids at a 1:1:1 mass ratio: a plasmid encoding the deactivated Cas9 (dCas9) nuclease (D10A and N863A) fused to the transactivation domain VP64, and a blasticidin-resistant gene; a plasmid encoding the MS2-p65-HSF1 fusion protein, and a hygromycin-resistant gene; a plasmid encoding a target-specific $20 \mathrm{nt}$ guide RNA (gRNA), and a puromycin-resistant gene. The positive cells were selected and cultured. Similar procedures were applied to generate MC38-con cells using control CRISPR activation plasmid.

Real-time PCR analysis. Total RNA was extracted using TRIzol (invitrogen). RNA was reverse transcribed using a Reverse Transcription kit (Applied Biosystems, Foster city, CA, USA). Real-time PCR was performed using SYBR green (Roche, Mannheim, Germany) on a Step One Real-time PCR System (Applied Biosystems). Expression data were normalised to GAPDH mRNA expression. Data were calculated as $2^{-\Delta \Delta \mathrm{Ct}}$. Primer sequences are listed in Supplementary information.

ELISA and human antibody cytokine arrays. Culture medium was collected and subjected to ELISA analysis. Human TGF $\beta 1$ and TGF $\beta 2$ concentration were measured by ELISA (Raybiotech) according to the manufacturer's protocols. Measurement and analysis of Antibody Cytokine Arrays for 40 kinds of cytokines associated with macrophage were provided by Raybiotech.

Luciferase reporter assays. The pGL3-STAT3 or pGL3-STAT3-mut (BOSHI Ltd., Harbin, China) was transfected into HT29, HT29-NC, and HT29-GFI1 cells using lipofectamine 2000 (Invitrogen). Luciferase activity was measured $48 \mathrm{~h}$ after transfection.

Migration and invasion assays. About 4000 cells were seeded into the upper chambers in $100 \mu \mathrm{l}$ of the culture medium containing $1 \%$ FBS. Transmigration of cells into the lower compartment containing $600 \mu \mathrm{l}$ medium (9\% FBS) occurred at $37^{\circ} \mathrm{C}$. After $24 \mathrm{~h}$, transwells were removed and cleaned with cotton swabs to remove non-migrated cells. Migrated cells adherent to the bottom of the membrane were stained with crystal violet (Sigma-Aldrich). Each determination was done at least in duplicates. Data are expressed as the number of migrating cells per field. For invasion assays, the upper chambers were coated with matrigel before using and the procedures were as above.

For monolayer wound-healing assays, a total of $3 \times 10^{5}$ cells were collected and plated in a six-well plate. At $100 \%$ confluence, two parallel wounds of $1 \mathrm{~mm}$ were made using a pipette tip. The number of cells crawling into the wound was measured after $24 \mathrm{~h}$, in three independent experiments.

Chromatin immunoprecipitation. Cells were cross-linked with $1 \%$ formaldehyde at room temperature for $10 \mathrm{~min}$, washed twice with $10 \mathrm{ml}$ ice-cold PBS, and then scraped into $0.5 \mathrm{ml}$ of lysis buffer and left on ice for $10 \mathrm{~min}$. Samples were treated according to the instructions of ChIP kit (Beyotime, Haimen, Jiangsu, China). Immunoprecipitations were performed overnight with GFI1 antibody (1$2 \mu \mathrm{g}$ ). Immune-complexes were captured by incubation with $40 \mu \mathrm{l}$ protein $\mathrm{A} / \mathrm{G}$ Sepharose. DNA extraction was performed using Qiagen Purification Kit. The samples were analysed by PCR using primers whose sequences are listed below.

STAT3 promoter-F: gggttagctgagcagtgacat

STAT3 promoter-R: aagctgataacgtgtagggct

PTGER2 promoter-F: gcgcattgtgtggtttggtt

PTGER2 promoter-R: acacagaagatcggggcaac
Animals. The DKO mice studies were approved by the Infection and Immunity Center of Chinese Academy of Sciences. DKO (BALB/c-Rag2 ${ }^{--} \mathrm{gc}^{-/-}$) mice were kindly provided by Professor Lieping Chen, Department of Immunology, Yale University School of Medicine, New Haven USA and used at age of 8-12 weeks. The mice were maintained under specific pathogen-free conditions in the animal facility at the Institute of Biophysics, Chinese Academy of Sciences, Beijing, China. The female C57BL/6 mice were purchased from YISI Laboratory Animal Technology Co., Ltd. (Changchun, China) and used at 10-week-old. The female nude mice were purchased from Beijing Vital River Laboratory Animal Technology Co., Ltd. (Beijing, China) and used at 6-week-old. These mice were maintained under specific pathogen-free conditions in Infection Key Laboratory of Heilongjiang Province, Harbin, China.

Xenograft experiments. Approximately $1 \times 10^{7}$ HT29-NC and HT29-GFI1 cells pretreated with/without LSMCM for $24 \mathrm{~h}$; or HT29-vector and HT29-shGFI1 cells were s.c. injected into the right flank of DKO or nude mice. Tumour growth was monitored every three days and tumour volumes were calculated by the equation $\mathrm{V}$ $\left(\mathrm{mm}^{3}\right)=a \times b^{2} / 2$, where $a$ is the largest diameter and $b$ is the perpendicular diameter.

Mouse in vivo metastasis studies. For in vivo metastasis assays, sixweek-old DKO or nude mice were housed in a specific pathogen-free facility. In total, $7 \times 10^{6}$ human CRC cells were suspend in $100 \mu \mathrm{l}$ culture medium and injected via the t.v. Mice were monitored every three days and body weights were measured. After 30,40 , or $60 \mathrm{~d}$, mice were killed, and lungs and livers were collected and the metastases were counted and analysed, respectively.

For CRC liver metastasis models, $1 \times 10^{6}$ MC38 or MC38-Gfi1 cells were suspended in $100 \mu$ l culture medium and injected into spleen of 10-week-old C57BL/ 6 females. Part of animals were killed $16 \mathrm{~d}$ after cell injection and analysed. ${ }^{60}$ Pathological changes were detected by H\&E staining on the liver. The survival curves of the other part animals were analysed until $50 \mathrm{~d}$ or longer by GraphPad Prism Software.

Statistical analysis. Statistical analyses were performed using the GraphPad Prism Software. D'Agostino \& Pearson normality test was performed prior to statistical analysis. For comparisons, Student's t-test (two-tailed) was used when normality test was achieved. Non-parametric test Mann-Whitney U-test was performed when normality test failed, Log-rank (Mantel-Cox) test was used for survival analysis, Pearson's correlation test was used to evaluate the expression relationships. A $P<0.05$ was considered significant.

Accession numbers. The mRNA expression data (TCGA, GSE17538, GSE41258, GSE14333 and GSE39582).

\section{Conflict of Interest}

The authors declare no conflict of interest.

Acknowledgements. We thank Dr Shoshana Yakar (New York University, USA) for kindly providing MC38 cell line. HT29-vector and HT29-shGFl1 cells were provided from Shenyang Bai Hao Biological Technology Co. Ltd. (Shen yang, China). This work is supported by grants from Natural Science Foundation of China (91229112, 30772238 and 81472367).

\section{Author contributions}

$X W$ designed, analysed and interpreted the experiments and wrote the manuscript. $X Y$ helped with human data acquisition and analysis. $L X$ and TL performed the lung metastasis model in vivo assays, Hematoxylin-eosin staining and 
immunohistochemistry. EL and JW helped with the CRC liver metastasis models and reviewed the manuscript. $\mathrm{ZH}$ and $\mathrm{JH}$ performed the cell culture and $\mathrm{CRC}$ cell metastatic behaviour experiments. $\mathrm{HX}$ and $\mathrm{HW}$ performed the immunohistochemistry analysis and animal models. MK, LX., WS, XH and ZF assisted with data analysis and manuscript preparation. $\mathrm{RH}$ led the study, supervised the overall project and reviewed the manuscript. All authors reviewed and approved of the submitted manuscript.

1. Belcheva A, Irrazabal T, Robertson SJ, Streutker C, Maughan H, Rubino S et al. Gut microbial metabolism drives transformation of MSH2-deficient colon epithelial cells. Cell 2014; 158: 288-299.

2. Gupta J, del Barco Barrantes I, Igea A, Sakellariou S, Pateras IS, Gorgoulis VG et al. Dual function of p38alpha MAPK in colon cancer: suppression of colitis-associated tumor initiation but requirement for cancer cell survival. Cancer Cell 2014; 25: 484-500.

3. Katoh H, Wang D, Daikoku T, Sun H, Dey SK, Dubois RN. CXCR2-expressing myeloid-derived suppressor cells are essential to promote colitis-associated tumorigenesis. Cancer Cell 2013; 24: 631-644.

4. Feagins LA, Souza RF, Spechler SJ. Carcinogenesis in IBD: potential targets for the prevention of colorectal cancer. Nat Rev Gastroenterol Hepatol 2009; 6: 297-305.

5. Luo JL, Maeda S, Hsu LC, Yagita H, Karin M. Inhibition of NF-kappaB in cancer cells converts inflammation- induced tumor growth mediated by TNFalpha to TRAlL-mediated tumor regression. Cancer Cell 2004; 6: 297-305.

6. Balkwill $F$, Charles KA, Mantovani A. Smoldering and polarized inflammation in the initiation and promotion of malignant disease. Cancer Cell 2005; 7: 211-217.

7. Wang K, Karin M. Tumor-elicited inflammation and colorectal cancer. Adv Cancer Res 2015; 128: 173-196.

8. Shalapour S, Karin M. Immunity, inflammation, and cancer: an eternal fight between good and evil. J Clin Invest 2015; 125: 3347-3355.

9. Tan W, Zhang W, Strasner A, Grivennikov S, Cheng JQ, Hoffman RM et al. Tumourinfiltrating regulatory $T$ cells stimulate mammary cancer metastasis through RANKL-RANK signalling. Nature 2011; 470: 548-553.

10. Kim S, Karin M. Role of TLR2-dependent inflammation in metastatic progression. Ann N Y Acad Sci 2011; 1217: 191-206.

11. Maeda S, Hikiba Y, Sakamoto K, Nakagawa H, Hirata $Y$, Hayakawa $Y$ et al. Ikappa B kinasebeta/nuclear factor-kappaB activation controls the development of liver metastasis by way of interleukin-6 expression. Hepatology 2009; 50: 1851-1860

12. De Rosa M, Pace U, Rega D, Costabile V, Duraturo F, lzzo P et al. Genetics, diagnosis and management of colorectal cancer (Review). Oncol Rep 2015; 34: 1087-1096.

13. Verma N, Keinan O, Selitrennik M, Karn T, Filipits M, Lev S. PYK2 sustains endosomalderived receptor signalling and enhances epithelial-to-mesenchymal transition. Nat Commun 2015; 6: 6064 .

14. Hassan WA, Yoshida R, Kudoh S, Hasegawa K, Nimori-Kita K, Ito T. Notch1 controls cell invasion and metastasis in small cell lung carcinoma cell lines. Lung Cancer 2014; 86: 304-310.

15. Calon A, Espinet E, Palomo-Ponce S, Tauriello DV, Iglesias M, Cespedes MV et al. Dependency of colorectal cancer on a TGF-beta-driven program in stromal cells for metastasis initiation. Cancer Cell 2012; 22: 571-584.

16. Gasparini G, Longo R, Sarmiento R, Morabito A. Inhibitors of cyclo-oxygenase 2: a new class of anticancer agents? Lancet Oncol 2003; 4: 605-615.

17. Wang D, Fu L, Sun H, Guo L, DuBois RN. Prostaglandin E2 promotes colorectal cancer stem cell expansion and metastasis in mice. Gastroenterology 2015; 149: 1884-1895 e1884.

18. Ma X, Aoki T, Tsuruyama T, Narumiya S. Definition of prostaglandin E2-EP2 signals in the colon tumor microenvironment that amplify inflammation and tumor growth. Cancer Res 2015; 75: 2822-2832.

19. Kaplan RN, Riba RD, Zacharoulis S, Bramley AH, Vincent L, Costa C et al. VEGFR1-positive haematopoietic bone marrow progenitors initiate the pre-metastatic niche. Nature 2005; 438 : 820-827.

20. von Karstedt S, Conti A, Nobis M, Montinaro A, Hartwig T, Lemke $J$ et al. Cancer cell-autonomous TRAIL-R signaling promotes KRAS-driven cancer progression, invasion, and metastasis. Cancer Cell 2015; 27: 561-573.

21. Xiao $\mathrm{Y}$, Fan $\mathrm{H}$, Zhang $\mathrm{Y}$, Xing $\mathrm{W}$, Ping $\mathrm{Y}$, Zhao $\mathrm{H}$ et al. Systematic identification of core transcription factors mediating dysregulated links bridging inflammatory bowel diseases and colorectal cancer. PLOS One 2013; 8: e83495.

22. Tili E, Michaille JJ, Wernicke D, Alder $\mathrm{H}$, Costinean $\mathrm{S}$, Volinia $\mathrm{S}$ et al. Mutator activity induced by microRNA-155 (miR-155) links inflammation and cancer. Proc Natl Acad Sci USA 2011; 108: 4908-4913.

23. Grimes HL, Chan TO, Zweidler-McKay PA, Tong B, Tsichlis PN. The Gfi-1 proto-oncoprotein contains a novel transcriptional repressor domain, SNAG, and inhibits $\mathrm{G} 1$ arrest induced by interleukin-2 withdrawal. Mol Cell Biol 1996; 16: 6263-6272.

24. Zeng H, Yucel R, Kosan C, Klein-Hitpass L, Moroy T. Transcription factor Gfit regulates self-renewal and engraftment of hematopoietic stem cells. Embo $J$ 2004; 23: 4116-4125.

25. Hock H, Hamblen MJ, Rooke HM, Schindler JW, Saleque S, Fujiwara Y et al. Gfi-1 restricts proliferation and preserves functional integrity of haematopoietic stem cells. Nature 2004; 431: 1002-1007.

26. van der Meer LT, Jansen JH, van der Reijden BA. Gfi1 and Gfiitb: key regulators of hematopoiesis. Leukemia 2010; 24: 1834-1843.
27. Zhu J, Guo L, Min B, Watson CJ, Hu-Li J, Young HA et al. Growth factor independent-1 induced by IL-4 regulates Th2 cell proliferation. Immunity 2002; 16: 733-744.

28. Park JH, Yu Q, Erman B, Appelbaum JS, Montoya-Durango D, Grimes HL et al. Suppression of IL7Ralpha transcription by IL-7 and other prosurvival cytokines: a novel mechanism for maximizing IL-7-dependent T cell survival. Immunity 2004; 21: 289-302.

29. Rodel B, Tavassoli K, Karsunky H, Schmidt T, Bachmann M, Schaper F et al. The zinc finger protein Gfi-1 can enhance STAT3 signaling by interacting with the STAT3 inhibitor PIAS3. Embo J 2000; 19: 5845-5855.

30. Bjerknes $M$, Cheng $H$. Cell Lineage metastability in Gfi1-deficient mouse intestinal epithelium. Dev Biol 2010; 345: 49-63.

31. Shrover NF, Wallis D, Venken KJ, Bellen HJ, Zoghbi HY. Gfi1 functions downstream of Math1 to control intestinal secretory cell subtype allocation and differentiation. Genes Dev 2005; 19: 2412-2417.

32. Fernandez-Pisonero I, Duenas Al, Barreiro 0 , Montero $O$, Sanchez-Madrid $F$, Garcia-Rodriguez C. Lipopolysaccharide and sphingosine-1-phosphate cooperate to induce inflammatory molecules and leukocyte adhesion in endothelial cells. J Immunol 2012; 189: 5402-5410.

33. Harizi H, Limem I, Gualde N. CD40 engagement on dendritic cells induces cyclooxygenase2 and EP2 receptor via p38 and ERK MAPKs. Immunol Cell Biol 2011; 89: 275-282.

34. Guo RX, Qiao YH, Zhou Y, Li LX, Shi HR, Chen KS. Increased staining for phosphorylated AKT and nuclear factor-kappaB p65 and their relationship with prognosis in epithelial ovarian cancer. Pathol Int 2008; 58: 749-756.

35. Williams TM, Leeth RA, Rothschild DE, Coutermarsh-Ott SL, McDaniel DK, Simmons AE et al. The NLRP1 inflammasome attenuates colitis and colitis-associated tumorigenesis. J Immunol 2015; 194: 3369-3380.

36. Foersch S, Sperka T, Lindner C, Taut A, Rudolph KL, Breier G et al. VEGFR2 signaling prevents colorectal cancer cell senescence to promote tumorigenesis in mice with colitis. Gastroenterology 2015; 149: 177-189 e110.

37. Sica GS, Fiorani C, Stolfi C, Monteleone G, Candi E, Amelio I et al. Peritoneal expression of Matrilysin helps identify early post-operative recurrence of colorectal cancer. Oncotarget 2015; 6: 13402-13415.

38. Noy R, Pollard JW. Tumor-associated macrophages: from mechanisms to therapy. Immunity 2014: 41: 49-61.

39. Yiakouvaki A, Dimitriou M, Karakasiliotis I, Eftychi C, Theocharis S, Kontoyiannis DL. Myeloid cell expression of the RNA-binding protein HuR protects mice from pathologic inflammation and colorectal carcinogenesis. J Clin Invest 2012; 122: 48-61.

40. Biswas S, Trobridge P, Romero-Gallo J, Billheimer D, Myeroff LL, Willson JK et al. Mutational inactivation of TGFBR2 in microsatellite unstable colon cancer arises from the cooperation of genomic instability and the clonal outgrowth of transforming growth factor beta resistant cells. Genes Chromosomes Cancer 2008; 47: 95-106.

41. Grivennikov SI, Greten FR, Karin M. Immunity, inflammation, and cancer. Cell 2010; 140: 883-899.

42. Igwe E, Kosan C, Khandanpour C, Sharif-Askari E, Brune B, Moroy T. The zinc finger protein Gfi1 is implicated in the regulation of lgG2b production and the expression of Igamma2b germline transcripts. Eur J Immunol 2008; 38: 3004-3014.

43. Yang J, Weinberg RA. Epithelial-mesenchymal transition: at the crossroads of development and tumor metastasis. Dev Cell 2008; 14: 818-829.

44. Voronov E, Shouval DS, Krelin Y, Cagnano E, Benharroch D, Iwakura Y et al. IL-1 is required for tumor invasiveness and angiogenesis. Proc Natl Acad Sci USA 2003; 100: 2645-2650.

45. Wu Y, Deng J, Rychahou PG, Qiu S, Evers BM, Zhou BP. Stabilization of snail by NF-kappaB is required for inflammation-induced cell migration and invasion. Cancer Cell 2009; 15: 416-428.

46. Zhang Y, Sime W, Juhas M, Sjolander A. Crosstalk between colon cancer cells and macrophages via inflammatory mediators and CD47 promotes tumour cell migration. Eur J Cancer 2013; 49: 3320-3334.

47. Solinas G, Schiarea S, Liguori M, Fabbri M, Pesce S, Zammataro L et al. Tumor-conditioned macrophages secrete migration-stimulating factor: a new marker for M2-polarization, influencing tumor cell motility. J Immunol 2010; 185: 642-652.

48. Wang S, Liu Z, Wang L, Zhang X. NF-kappaB signaling pathway, inflammation and colorectal cancer. Cell Mol Immunol 2009; 6: 327-334.

49. Klampfer $\mathrm{L}$. The role of signal transducers and activators of transcription in colon cancer. Front Biosci 2008; 13: 2888-2899.

50. Terzic J, Grivennikov S, Karin E, Karin M. Inflammation and colon cancer. Gastroenterology 2010; 138: 2101-2114, e2105.

51. Taniguchi K, Karin M. IL-6 and related cytokines as the critical lynchpins between inflammation and cancer. Semin Immunol 2014; 26: 54-74.

52. Polytarchou C, Hommes DW, Palumbo T, Hatziapostolou M, Koutsioumpa M, Koukos G et al. MicroRNA214 is associated with progression of ulcerative colitis, and inhibition reduces development of colitis and colitis-associated cancer in mice. Gastroenterology 2015; 149: 981-992.

53. Castellone MD, Teramoto H, Gutkind JS. Cyclooxygenase-2 and colorectal cancer chemoprevention: the beta-catenin connection. Cancer Res 2006; 66: 11085-11088.

54. Aggarwal BB, Shishodia S, Sandur SK, Pandey MK, Sethi G. Inflammation and cancer: how hot is the link? Biochem Pharmacol 2006; 72: 1605-1621.

55. Chen WS, Wei SJ, Liu JM, Hsiao M, Kou-Lin J, Yang WK. Tumor invasiveness and liver metastasis of colon cancer cells correlated with cyclooxygenase-2 (COX-2) expression and inhibited by a COX-2-selective inhibitor, etodolac. Int J Cancer 2001; 91: 894-899. 
56. Zhang XH, Jin X, Malladi S, Zou Y, Wen YH, Brogi E et al. Selection of bone metastasis seeds by mesenchymal signals in the primary tumor stroma. Cell 2013; 154: 1060-1073.

57. Klein CA. Selection and adaptation during metastatic cancer progression. Nature 2013; 501: 365-372.

58. Dupaul-Chicoine J, Arabzadeh A, Dagenais M, Douglas T, Champagne C, Morizot A et al. The Nlrp3 inflammasome suppresses colorectal cancer metastatic growth in the liver by promoting natural killer cell tumoricidal activity. Immunity 2015; 43: 751-763.

59. Vanharanta S, Massague J. Origins of metastatic traits. Cancer Cell 2013; 24: 410-421.

60. Sanchez-Lopez E, Flashner-Abramson E, Shalapour S, Zhong Z, Taniguchi K, Levitzki A et al. Targeting colorectal cancer via its microenvironment by inhibiting IGF-1 receptor-insulin receptor substrate and STAT3 signaling. Oncogene 2015; 35: 2634-2644. (c) (1) This work is licensed under a Creative Commons Attribution-NonCommercial-ShareAlike 4.0 International License. The images or other third party material in this article are included in the article's Creative Commons license, unless indicated otherwise in the credit line; if the material is not included under the Creative Commons license, users will need to obtain permission from the license holder to reproduce the material. To view a copy of this license, visit http://creativecommons.org/licenses/by-nc-sa/4.0/

(C) The Author(s) 2017

Supplementary Information accompanies this paper on Cell Death and Differentiation website (http://www.nature.com/cdd) 